Aus der Deutschen Forschungsanstalt für Psychiatrie in München.)

\title{
Die zentralen Veränderungen beim Fleckfieber und ihre Bedeutung für die Histopathologie der Hirnrinde. ${ }^{1}$ )
}

\author{
Von \\ W. Spielmeyer. \\ Mit $10 \mathrm{~T}$ afeIn.
}

(Eingegangen am 15. Februar 1919.)

Die Entdeckungen Eugen Fränkels über die Histopathologie des Fleckfiebers sind bekannt. Ich brauche deshalb meinem Aufsatz keine ins einzelne gehende Einführung zu geben. Ich erinnere nur daran, daß es Frän kel schon vor dem Kriege (1913) gelungen war, das anatomische Substrat der Hautroseolen bei dieser Krankheit aufzufinden, nämlich partielle, meist sektorenförmige Wandnekrosen an kleinsten Arterien mit knötchenförmiger perivasculärer Zellwucherung. In der Wandnekrose, die meist auf umschriebene Teile der Intima beschränkt ist, sah Fränkel das Grundlegende des Prozesses. Das Gros der Zellen des Knötchens seien Abkömmlinge adventitieller und periadventitieller Bindegewebszellen. Dieser Befund schien Fränkel so charakteristisch, daß er für zweifelhafte klinische Fälle das Herausschneiden der Hautroseolen und die anschließende histologische Untersuchung zur Sicherstellung der Diagnose empfahl. Schon im Jahre 1914 konnte Fränkel weiter den Nachweis führen, daß die von ihm gefundenen Veränderungen an der Stelle der Hautroseolen in prinzipiell gleichartiger Weise auch in inneren Organen, so besonders im Gehirn, Herzfleisch, Leber und Magendarmkanal vorkommen. Zu diesen Befunden äußert sich Frä nkel selbst in einem Prioritätsstreit (Oktober 1917): ,Ich hoffe, nun definitiv dargetan zu haben, daß ich tatsächlich als erster die Erkrankungen kleinster Arterien mit begleitender Knötchenbildung an der Haut wie an inneren Organen bei Fleckfieberkranken gefunden und geschildert habe."

An der gleichen Stelle äußert sich Fränkel auch dahin, daß andere Beobachter, wie vor allem Kyrle, Benda, Bauer und Ceelen eine

1) Nach einem am 21. XI. 1918 in der wissenschaftlichen Sitzung der ,Deutschen Forschungsanstalt für Psychiatrie" gehaltenen Vortrage.

Z. f. d. g. Neur. u. Psych. O. XLviI. 
prinzipielle Bestätigung seiner Angaben geliefert haben. Aus diesen späteren Arbeiten erwähne ich hier eine Feststellung von Aschoff und von Benda. Während Fränkel das Fehlen von Leukocyten in den Fleckfieberherden betont hatte, hat Aschoff wohl als erster hervorgehoben, daß in den Frühstadien Leukocyten nicht fehlten. Und Benda bemerkt ausdrücklich, daß die Leukocyten zum Teil sehr reichlich an den frischen Roseolen beteiligt seien. Daß einer Infiltration mit Rundzellen auch Plasmazellen beigemengt sind, erwähnt G. B. Gruber.

Von den Arbeiten, die sich vorwiegend mit den Herden im Gehirn beschäftigt haben, nenne ich die von Ceelen und von Herzog. Ceelen stellte fest, daß die Fränkelschen Knötchen - die übrigens auch Provazek bei experimentellem Fleckfieber im Affengehirn gesehen hatte - in besonders großer Zahl im Gehirn angetroffen werden; und Herzog sagt, daß die rein anatomische Diagnose auf Fleckfieber gerade auf Grund der Gehirnuntersuchung zu stellen sei. Auch Ceelen findet, wie Aschoff, Benda u. a., mehrkernige Leukocyten in den Herden und spricht von einer Paarung von produktiver und exsudativer Entzündung. Herzog, der ein besonders großes Material aus verschiedenen Phasen der Frkrankung untersuchen konnte, bezieht die Herdbildung, wie Fränkel, auf eine umschriebene Intima- bzw. Gefäßwandnekrose. Die Zellen des Knötchens schrieben sich auch im Gehirn vorwiegend von Gefäßwandzellen her; daneben fänden sich verschiedenartige weiße Blutzellen und ihre Fortentwicklungsformen. Endlich erwähne ich noch Schröders Demonstration von Hirnbefunden bei Fleckfieber. Er hält die Annahme Fränkels, daß umschriebene Gefäßwandveränderungen das Primäre sind, für zutreffend; die Gliawucherung sei die Folge der lokalen Gewebsnekrobiose. Leukocyten fand er in den Herden nicht.

Das Material von Fleckfieber, welches ich untersuchen konnte, umfaßt in ganzen 12 Fälle. Ich verdanke es besonders der großen Liebenswürdigkeit und Freigebigkeit des Herrn Prof. Oberndorffer, ferner Herrn Prof. Groß, der die Güte hatte, dem Institute ein großes und wertvolles Untersuchungsmaterial aus dem Felde zu übersenden, und den Herren Prof. B. G. Gruber und Schmincke. Bei vielen Fällen hatte ich Gelegenheit, mit den Hirn- und Rückenmarksbefunden auch die Präparate von anderen Organen und von der Haut zu vergleichen. Ich beschränke mich jedoch hier bei der Schilderung meiner Feststellungen lediglich auf das, was ich am Zentralnervensystem sah. Natürlich konnte nicht jeder meiner Fälle bis in alle Einzelheiten durchstudiert werden, zumal mir auch von manchen nur wenige Stücke zur Verfügung standen; eine ausführliche neurohistologische Untersuchung durch das ganze Zentralorgan wurde in 4 Fällen vorgenommen. 


\section{Utbersichtsbilder.}

Das Auffallendste in dem anatomischen Gesamtbilde ist natürlich die Ausstreu ung von Herden über das Zentralnervensystem. Am besten orientiert man sich darüber am Nissl-Präparat. Ein Schnitt, wie ihn Mikrophotogramm 1 wiedergibt, zeigt ein häufig wiederkehrendes Bild von einem Falle, wo die Herde in der Großhirnrinde besonders zahlreich sind. Hier sieht man also in einem größeren Gesichtsfelde schon mehrere Herde. Sie haben die bekannte, oft erwähnte Knötchenform. Sie sind meistens kugelig, auch oval ausgezogen; manchmal schärfer von der Umgebung abgehoben, manchmal undeutlicher begrenzt. Oft sind sie von einem Spalt im Zentrum durchzogen - einem Einriß des lockeren Zellgefüges infolge der Fixierung. Einen oberflächlichen Maßstab für ihre Größe gibt die Breite der betreffenden Rindenschicht, in der sie liegen, oder auch die Größe der umgebenden Ganglienzellen. Will man sich genauer über Volumen und Gestalt der Herde orientieren, so muß man Serien durchmustern (s. u.).

Die Herde sind über das ganze Zentralnervensystem verbreitet. In allen meinen Fällen war das so, daß sie sowohl im Gehirn, wie im Hirnstamm, Kleinhirn und Rückenmark liegen. In der Pia waren sie bei keinem meiner Fälle zu sehen. Sie haben gewisse Prädilektionsstellen, wo sie besonders gehäuft vorkommen. Nach dem, was ich sah, pflegen die tiefen Abschnitte der Brücke und des verlängerten Markes am reichlichsten von Herden durchsetzt zu sein, dann etwa kommt die oberste Kleinhirnrinde, das Höhlengrau, die Rinde des Großhirns und endlich das Rückenmark.

Sehr auffallend sind die Beziehungen der Herde zur grauen Substanz, wenigstens am Gehirn selbst; ganz allgemein kann man sagen, daß hier die Herde im Markweiß relativ selten sind. Nur am Rückenmark fiel mir ein solcher Unterschied zwischen grauer und weißer Substanz nicht auf. Hier ist, soweit ich an einem allerdings nur kleinen Material zu sagen vermag, das Markweiß etwa ebenso häufig von den herdförmigen Veränderungen betroffen, wie die graue Substanz, oft sitzen sie gerade an der Grenze zwischen beiden. Im Großhirn aber ist die eben erwähnte Prädilektion der Herde in den grauen Massen sehr ausgesprochen. Es ist in den Fällen, die ich genauer untersuchen konnte, eine Rarität, da $\beta$ einmal ein Herdchen in dem eigentlichen kompakten Markweiß, im Centrum semiovale, sitzt. Im Markweiß der einzelnen Windung, im „Markradius“, sieht man nicht so selten einmal ein Herdchen, obschon auch dieser sehr viel weniger Herde führt als die Rinde. Meistens halten sie sich auch dann an die tiefe Rinde, bzw. an jene Zone des Markradius, wo noch verstreute 
Ganglienzellen liegen. Ein gleichartiges Verhalten habe ich auch im Kleinhirnmark feststellen können. Die Hauptmasse des Markweißes ist auch dort so gut wie ganz frei von Herden. In den Radien der Windungen sieht man aber ab und zu einmal einen Herd (Abb. 3 bei $h$ ). Auch feinere Herdchen von nicht ausgesprochener Knötchenform gibt es in den Kleinhirnradien. Mit der Annäherung an die im Kleinhirn gelegenen großen Kerne, zum Beispiel den Nucleus dentatus, trifft man dann wieder in dessen unmittelbarer Begrenzung und in ihm selbst vereinzelte Herdchen, ähnlich wie im Großhirn beim t'bergang des Centrum semiovale in die basalen Ganglien.

Es scheint, daß es in derGro Bhirn ninde eine gewisse Bevorzugung bestimmter Schichten gibt. In den Fällen mit zahlreichen Herden war in vielen Gebieten die 2. bis 5 . Brod ma n n sche Schicht besonders regelmäßig und erheblich von Herden durchsetzt. Dort ist wohl der Ha uptsitz der Herde gelegen. Freilich erscheinen dann wieder in anderen Regionen des gleichen Falles und in anderen Fällen die Herde ganz regellos über das Rindenband bald in dieser, bald in jener Schicht verstreut. Manchmal ist es auch gerade die oberste Schicht, die in einem Präparat mehrere Herde zeigt, oder auch die 6. Brod man n sche Schicht mit ihrem Utbergang zum Markradius. Ich möchte deshalb nur mit Vorbehalt sagen, daß die mittleren Schichten der Rinde mehr betroffen sind als die anderen. Auch scheint es mir, daß die Höhe der Windung durchschnittlich mehr Herde führt als der Grund der Furchen.

Wie man es in Anbetracht der außerordentlichen Verschiedenheit in der Intensität der Hautroseola erwarten durfte, so ist auch im Gehirn die Zahl und Ausbreitung der Herde in den einzelnen Fällen sehr verschieden, und es gibt Fälle - wie z.B. der, von dem Bild l stammt -, wo in jedem Schnitte von einer Windung eine Reihe von Herden liegen - 6-8 und 'mehr -, und andere, wo man nur 1 oder 2 Herde sieht. Es gibt natürlich auch Gehirne, in denen sie viel seltener sind, und wo man von manchen Regionen viele Schnitte durchsehen kann, ehe man auf einen Herd trifft. Aber eine so geringe Aussaat von Herden über das Großhirn scheint mir nach meinem Material selten zu sein. In solchen Fällen mit relativ wenigen Großhirnherden waren die Veränderungen - wie schon erwähnt - an den Prädilektionsstellen der Herdbildung, also in den tiefen Abschnitten des Hirnstammes viel reichlicher.

Soweit ich es an meinem beschränkten Material ermitteln konnte, bestehen sichere regionäre Unterschiede bezüglich der Erkrankung der einzelnen Teile des Großhirns nicht. Insbesondere muß festgestellt werden, daß die motorische Region, der Stirn-, Parietal- und Schläfenlappen, die Ammonshornregion keine erkennbaren Differenzen 
in der Stärke und Extensität des Prozesses aufweisen. Nur das fiel mir auf, daß der Occipitallappen in drei Fällen, wo ich größere Partien davon untersuchen konnte, sehr viel geringer von Herden durchsetzt war, als die übrigen. Teile des Großhirnmantels. In dieser Richtung muß ein größeres Material noch Aufschluß bringen, ob es sich hier nur um Zufälligkeiten handelt. Die Frage hat natürlich deshalb Bedeutung, weil bekanntlich manche im übrigen diffuse Prozesse den Occipitallappen relativ wenig ergreifen.

Das Mikrophotogramm 2, welches über die Verteilung der Herde im Kleinhirn orientieren soll, stammt von einem Fall mit besonders reichlichen Kleinhirnrindenherden. Es ist eine Stelle ausgesucht worden, bei der man in einem Gesichtsfeld viele Herdchen sieht; das Utbersichtsbild zeigt neben den ausgesprochen knötchenförmigen kompakten Herden auch die Pole eines Herdes: die Auflockerung des Herdes in seiner Peripherie. Ergänzt wird dieses Bild noch durch Abb. 3, wo sich neben den Herden in der Molekularschicht noch anders lokalisierte Herde finden. Im Kleinhirn erweist sich nämlich die Molekularschicht als eigentliche Prädilektionsstelle für die herdförmigen Veränderungen; die Herde sitzen hier ganz überwiegend in der zellarmen Oberflächenzone. Die übrige Rinde des Kleinhirns ist viel weniger von Herden durchsetzt, am häufigsten noch die Grenzzone zwischen Körner- und Molekularschicht; wie z. B. bei $h$ in Abb. 3 auf der Höhe der Purkinjeschen Zellen. Ziemlich selten sind sie in der Körnerschicht. Das Markscheidenpräparat (Mikrophotogramm 14) zeigt einen solchen Herd. Erwähnt hatte ich schon die relative Seltenheit der Herde im Markradius und ihr fast völliges Fehlen in dem kompakten Markkörper der Kleinhirnsubstanz.

Was ich früher über die Bevorzugung der grauen Substanz durch die Herde sagte, wird durch die Befunde im Hirnstamm besonders gut illustriert. Man sieht hier gewiß vereinzelte Herdchen auch einmal im Markweiß. Aber im allgemeinen halten sie sich auch dort, wo die grauen Kerne in Einzelgruppen zersprengt sind, gerne an solche Ganglienzellnester (vgl. Serie 19). Das Mikrophotogramm von den unteren und lateralen Partien der Brücke (Abb. 5) zeigt ebenfalls die Herde in den Brïckenkernen. Besonders deutlich war mir dieses Verhalten in allen Fällen gerade in der Gegend des Olivenbandes erschienen: nur selten liegen die Herdchen außerhalb, oft halten sie jenes ausschließlich besetzt (Mikrophotogramm 4). - Von der Lokalisation der Herde im Rückenmark war vorher schon die Rede.

Das Ủbersichtsbild zeigt nun außer den Herden noch zwei andere auffällige Eigentümlichkeiten, die in keinem meiner Fälle fehlten; das ist zunächst - als zweiter Hauptfaktor im histologischen Gesamtbilde dieses Prozesses - die Infiltration zentraler 
Gefäße. Dieses anatomische Symptom ist allerdings in seiner Intensität und Ausbreitung überaus wechselvoll, und zwar sowohl in den verschiedenen Fällen, wie auch im gegebenen Falle in den einzelnen Regionen des Zentralnervensytems. Aber. ich habe es, wie gesagt, nie vermißt. Besonders klar treten die Gefäßinfiltrationen schon im Utbersichtsbild bei solchen Fällen hervor, wo die Herde besonders zahlreich sind. An den bisher besprochenen Ubersichtsphotogrammen sieht man solche Infiltrate, besonders deutlich an den größeren Gefäßen bei Abb. 1. Es fällt aber schon an diesem Präparat auf, daß auch präcapillare Gefäße stärker hervortreten, als sie das normalerweise tun würden, da sie hier eben Infiltrate in ihren Adventitialräumen beherbergen. Das gleiche gilt von dem Brückenbild (5), wo bei ig zwei schräg getroffene Gefäße starke Zelleinlagerungen führen. Das Mikrophotogramm vom Kleinhirn läßt ebenfalls einige infiltrierte Gefäße in der Rinde und im Mark erkennen. An dieser Abb. 2 fällt nun etwas auf, was andere Bilder noch in den Einzelheiten zeigen werden, nämlich, daß in der Nähe eines Herdes ein Gefäß durch Infiltrate besonders stark herausgehoben ist. Während das bei dem t'bersichtsbild von Großhirn und von der Brücke nicht deutlich wird, ist es hier und an dem Olivenbild recht ausgesprochen: in der unmittelbaren Um. gebung der Herde zeigen einzelne Gefäße ein besonders kräftiges Infiltrat. Immerhin ist in diesen Präparaten die Gefäßinfiltration auch sonst ziemlich lebhaft. Viel klarer ist an den Mikrophotogrammen 6 und 12 die Heraushebung eines ei n zel n e n Gefäßes durch die Infiltrate. Es wird sich zeigen, daß es sich hier häufig nicht um das „Herdgefäß" handelt (nämlich das Gefäß, welches in den Herd eintritt), sondern öfters um das größere Gefäß, welches einen Zweig zum Herd abgibt oder aber auch nur um irgendeine in der Nähe gelegene kleine Arterie.

Von besonderer Wichtigkeit sind jedoch solche Präparate, bei denen ein Zusammenhang zwischen Herden und Infiltration nicht besteht. Es gibt Stellen, wo man relativ lange suchen muß, bis man einen Herd findet, und wo die Großhirnrinde ausgesprochene Infiltrationen ihrer Gefäße aufweist. Wenn ich auch im allgemeinen gerade dort, wo reichlich Herde sind, auch reichliche Infiltrationen sah, so gibt es eben doch Partien, wo geradezu ausschließlich infiltrative Vorgänge an den Gefäßen zu beobachten sind, unabhängig von jeder Herdbildung. Das Mikrophotogramm 7 gibt davon ein Bild. Man sieht einige größere Gefäße mit deutlichen Zellmänteln; daneben heben sich auch die feineren Gefäße durch die Einlagerung von Zellelementen heraus. Schon das Ubersichtspräparat zeigt hier wie an an deren Mikrophotogrammen, daß diese Infiltrationen nicht herdförmig sind und daß sie sich an die Gefäßscheiden halten. 
Das dritte anatomische Symptom der Miterkrankung des Zentralnervensystems beim Fleckfieber ist die Einlagerung von Zellen in die weichen $\mathrm{Häute}$ des Gehirns und Rückenmarks (welche übrigens in keinem meiner Fälle „Herde" enthielten). Auch dieses Zeichen ist konstant und muß deshalb als ein wichtiger Zug im histólogischen Gesamtbilde dieses Prozesses bewertet werden. Ich betrachte hier diese Infiltration oder - um einen noch vorsichtigeren Ausdruck zu gebrauchen - Zelleinlagerung in die Meningen getrennt von der Infiltration der zentralen Gefäße, weil es sich dabei im allgemeinen um verschiedenartige histopathologische Bilder handelt, die bei der genauen histologischen Analyse der eingelagerten Zellen klar werden. Während nämlich das Infiltrat - wenn ich dies hier vorwegnehmen darf - an den Gefäßen ganz überwiegend aus Plasmazellen und anderen lymphocytären Elementen besteht, wird die Eigenart des Infiltrates der Piamaschen durch Makrophagen bestimmt.

Das läßt sich wohl schon im Utbersichtsbild, wenigstens im groben erkennen. Wenn man das Photogramm 8 betrachtet, so sieht man in der zwischen den Windungen ausgespannten Partie der Pia vorwiegend große helle Elemente - Makrophagen - neben wenigen dunklen Zellen. Diese dunklen Plasmazellen gewinnen das Utbergewicht in der Pialamelle des Sulcus, besonders in der Umgebung zweier quer getroffener Gefäße.

Der Zellreichtum in der Pia wechselt sowohl in den verschiedenen Fällen wie auch in den verschiedenen zentralen Partien des Einzelfalles außerordentlich. Über der Windungskuppe stellt sich das Úbersichtsbild der Pia im allgemeinen so dar wie in Abb. 1. Abb. 8 illustriert das durchschnittliche Verhalten der Meningen über einer Furche. Hier ist das Infiltrat sehr viel reicher als dort, wo die Pia der Kuppe der Windung enger aufliegt. An manchen anderen Partien des Großhirns ist der Zellgehalt recht intensiv, besonders dort, wo größere Gefäße und derbere meningeale Balken liegen. Im großen und ganzen kann man sagen, da $\beta$ diese meningealen Veränderungen am stärksten in den Fällen sind, wo auch die Herde sehr zahlreich sind. Aber nur mit erheblicher Einschränkung gilt das auch für die betreffende Rindenregion ein und desselben Falles: wo die Herde zahlreich sind, ist wohl im allgemeinen auch der Zellgehalt der Pia ziemlich groß. Doch muß andererseits ausdrücklich hervorgehoben werden, daß auch über Windungen und besonders über Furchen, wo das Rindenband nur ganz wenige Herde enthält (wie z. B. in der Hinterhauptspartie) die Zelleinlagerung eine sehr reiche sein kann. Einer meiner Fälle mit relativ wenigen Herden im Großhirn zeigte doch über der Hinterhauptrinde ein stellenweise recht starkes Infiltrat.

Ein unmittelbares Úbergreifen des Piainfiltrates auf die Rinden- 
substanz ist nirgends zu sehen. Auch setzt sich das Infiltrat nicht in der Form auf die einstrahlenden Rindengefäße fort, daß - wie etwa bei der Hirnlues - der Zellmantel eines Gefäßes von dessen Eintrittsstelle in die Rinde im weiteren Verlaufe durch diese allmählich abnimmt. Es besteht vielmehr gar keine derartige Abhängigkeit der Zellinfiltrate der Rindengefäße von der Zellmasse der weichen Häute. Besonders findet man keinen Parallelismus zwischen der Stärke des Zellgehaltes in der Pia und der Intensität und Ausbreitung der adventitialen Infiltrate in der Rinde. Das zeigen schon die hier wiedergegebenen Utbersichtsbilder auch von den übrigen Abschnitten des Zentralorgans.

Wie groß die Unterschiede auch in dem Zellgehalte der Kleinhirnpia in den einzelnen Stellen des gleichen Falles sind, lehrt Abb. 2 u. 3. In Abb. 2 ist der Zellgehalt gering, während er bei dem Präparat 3 sehr intensiv ist. Das Piainfiltrat ist an den Falten sehr wechselnd stark; in einer fast zellfreien Lamelle treten fleckweise stärkere Zelleinlagerungen hervor wie gerade in dem Spalt der Abb. 2. An diesem Mikrophotogramm ist auch unterhalb des großen, schräg angeschnittenen Gefäßes ein Saum von tiefschwarzen, dichtgedrängten Zellen sichtbar; es handelt sich da um die ziemlich häufige streifenförmige Einlagerung von Plasmazellen in den sogenannten subpialen Spalt.

In allen Fällen, die ich untersuchen konnte, war am Rückenmark und schon am Hirnstamm der Zellgehalt der weichen Häute sehr viel geringer als besonders über dem Großhirn. Photogramm 5 veranschaulicht das an einem Schnitt von der Brücke. Das bestätigt übrigens, was vorhin schon für das Großhirn hervorgehoben wurde, daß auch über herdereichen Partien das Infiltrat gering sein kann, ebenso wie das Umgekehrte vorkommt. Denn gerade an den basalen Abschnitten der Brücke und des verlängerten Markes waren in den Fällen, wo ich größere Partien davon untersuchen konnte, die Herde immer ganz besonders zahlreich.

So orientiert schon das Ưbersichtsbild über die drei wesent lichsten Züge des histologischen Prozesses beim .Fleckfieber. Die Veränderungen am Zentralnervensystem bei dieser Infektionskrankheit werden nicht nur durch die Herde, sondern auch durch die Zelleinlagerungen in die weichen Häute und durch die Infiltrationen zentraler Gefäße charakterisiert; wir müssen die beiden letzteren anatomischen Symptome als gleichwertige Faktoren im histologischen Gesamtbild neben die Herde stellen. Denn die Zelleinlagerungen in die Meningen und die Infiltrationen werden in keinem der Fälle vermißt. Sie sind auch nicht etwa nur Attribute oder Begleiterscheinungen der Herdbildung. Gewiß sind beide im allgemeinen in den Fällen am stärksten ausgebildet, wo auch die Herde besonders reichlich sind. Aber darin 
drückt sich eben nur die Intensität der Miterkrankung des Zentralnervensystems aus. Es bestehen zwischen jenen anatomischen Hauptsymptomen keine unmittelbaren lokalen Beziehungen; denn wenn wir auch als bemerkenswerte Eigentümlichkeit eine intensive Zelleinlagerung in eines oder einige wenige Gefäße der unmittelbaren Umgebung des Herdes fanden, so werden doch auch ganz unabhängig von jeder Herdbildung mehr diffuse Infiltrationen beobachtet. Und für die Meningen gilt ebenfalls, daß eine lokale Parallele zwischen starker Herdbildung und starker Zelleinlagerung nicht besteht; ich verweise nur auf die Präparate von der Brücke.

\section{Serienbilder.}

Ich sagte schon, daß über die gröbere Konfiguration der Herde nicht das einzelne Präparat sicher entscheiden kann, sondern daß wir dafür Serienschnitte zu Rate ziehen müssen. Ich bringe hier Bilder ${ }^{1}$ ) aus drei verschiedenen Serien. Zunächst eine Reihe von Schnitten aus einem Brückenkern. Diese Photogramme geben Aufschluß über zwei Fragen, nämlich erstens, wieweit sich d urchschnittlich ein gewöhnlicher knötchenförmiger Herd verfolgen läßt; und zweitens, ob neben den gewöhnlichen größeren Herden auch kleine vorkommen. Diese letztere Frage läßt sich ja deshalb nicht im einzelnen Schnitt entscheiden, weil ein darin sich präsentierender kleiner Herd nur der Pol eines größeren sein könnte. In der Brückenserie, die hier wiedergegeben ist, sieht man nun vom 4. Schnitt ab ein kleines Herdchen, welches nach zwei weiteren Schnitten wieder verschwindet. Der gewöhnliche große Herd dagegen ist durch die ganze hier wiedergegebene Reihe von Mikrophotogrammen zu verfolgen. Das ist etwa das durchschnittliche Maß für einen gewöhnlichen Herd, wie wir es hier ablesen können, nämlich, daß er sich über 7-8 Sch nitte bei einer Schnittdicke von $15 \mu$ verfolgen läßt. Es gibt aber auch umfangreichere, wo sich der Herd in seinem größten Durchmesser über 10 solcher Präparate ausdehnt. Es ergibt sich daraus, daß ein Herd durchschnittlich 0,1 bis $0,12 \mathrm{~mm} \mathrm{D}$ urchmesser hat. Häufiger als die ungewöhnlich großen (von etwa $0,15 \mathrm{~mm}$ ) sind kleinere, die man nur über 3-4 Schnitte verfolgen kann, die - wie der kleine Herd in der Brückenserie also nur etwa halb so groß sind, wie die meisten Knötchen. Eine Ergänzung finden diese Serienphotogramme noch durch die Abb. 25a und $b$, wo ein kleiner Herd sich nur über zwei Schnitte hin ausdehnt, sich also in seinem größten Durchmesser bloß über $30 \mu$ erstreckt.

1) Anmerkung bei der Korrektur: Bezüglich der Wiedergabe der Mikrophotogramme der Serien sei auf die Anmerkung zu der Figurenerklärung (S. 49) verwiesen. 
In der Großhirnrinde stellen sich kleinste Herde - welche, wie das Serienbild lehrt, nicht etwa nur die Enden eines typischen Knötchens sind -- als Flecken von 6-8 Gliazellen dar, die sich gern in einen Gefäßwinkel schmiegen und durchschnittlich nur in einem Schnitte zu sehen sind. Hat man auf diese Herde erst achtgegeben, so entdeckt man, daß sie viel häufiger sind, als es zunächst scheint. Viele von den Zellansammlungen an den Gefäßchen in der Großhirnrinde und in anderen Teilen des Zentralorgans erweisen sich also nicht als die Enden eines Herdes, sondern sie sind ganz kleine Herdchen. Und die genauere Analyse solcher Herdchen zeigt, daß es sich hier keineswegs immer um junge Herde handelt, sondern sie sind nicht selten wohl ebenso alt wie die Knötchen von Durchschnittsgröße, da man auch an ihnen öfters regressive Umwandlungen der Zellelemente nachweisen kann. Manche aber dürfen als wirklich junge und noch nicht völlig entwickelte Herde angesprochen werden.

Das Serienbild gibt nun nicht nur über Umfang und Verschiedenheiten des Volumens, sondern auch über besondere Qualitäten der Herde Auskunft. Schon am Einzelschnitt kann man nicht so selten wahrnehmen, daß manche Herde einen merkwürdig lockeren Bau haben und die Zellkomplexe hier nicht das durchschnittliche kompakte Gefüge aufweisen. Aber auch bezüglich der Beurteilung dieser Dinge sagt natürlich das Einzelpräparat nichts Sicheres aus, da man ja auch hier nicht bestimmt entscheiden kann, wie denn der Herd etwa in den nächstfolgenden Schnitten gestaltet ist.

Bei der Durchsicht der Serien ergeben sich drei hauptsächliche Abweichungen oder Modifikationen von der gewöhnlichen Knötchenform: Erstens haben manche Herde eine „Rosettenform", so besonders in der obersten Schicht der Großhirnrinde Ich habe für deren Illustration drei Präparate aus einer Rindenserie ausgewählt. (Es ist bei der Reproduktion ${ }^{1}$ ) aus äußeren Gründen immer ein Photogramm bzw. ein Schnitt übersprungen.) Das Charakteristische daran ist, daß sich um ein Gefäß (das 2 Schnitte vor dem ersten Präparat in die Rinde eingetreten ist) stäbchen- und wurstförmige Elemente gruppieren, die dann weiterhin an Zahl und auch an Ausdehnung des Zellplasmas zunehmen; sie erscheinen an diesem Gefäße wie verankert und streben von dort, ihm vielfach senkrecht aufsitzend, nach allen Seiten, so daß in dem nächstfolgenden Schnitte das Bild des ,Rosetten herdes" resultiert. Zwei Schnitte weiter ist dann die Rosettengestalt des Herdes schon geschwunden, und es liegen hier sehr verschieden gestaltete Gliazellen, zum Teil wieder stäbchen- und wurstförmige Elemente neben anderen, die eine mehr spinnen- und sternartige Gestalt haben; das Gefäß hat sich bereits ziemlich weit von seinem

1) S. Anmerkung S. 49. 
Eintritt in die Pia entfernt. Der letzte Schnitt stellt den unteren Pol dieses Rosettenherdes dar.

Solche „Rosettenherde" sind, wie ich schon sagte, in der obersten Schicht der Großhirnrinde nichts Seltenes. Oft spannen sich die Gliazellen zwischen dem eigentlichen Herdgefä $B$ und den umgebenden Gefäßen so aus, daß das Rosettenherdchen mit den plasmatischen Fortsätzen seiner Zellen wie ein Spinnengewebe an den Nachbargefäßen hängt. Auch im Kleinhirn habe ich solche Herdchen gesehen, und zwar liegen sie hier ebenfalls in der Oberflächenzone. Es scheint also, daß diese besondere Art der Herdehen im Zusammenhange steht mit den lokalen Bedingungen (s. S. 42). unter denen sie sich entwickeln. Immerhin sieht man in der obersten Zone der Groß- und Kleinhirnrinde auch gewöhnliche Knötchen.

Die zweite a uffälligste Modifikation habe ich im Kleinhirn gefunden. In einem meiner Fülle überraschen die Bilder von der Molekularschicht durch merkwürdige lockere gliöse Verbände, die wie ein „strauchartiges" Geflecht erscheinen. In den Serien läßt sich zwar für einige von diesen Bildungen nachweisen, daß sie Pole gewöhnlicher Knötchen sind (Abb. 2 u. $3 p h$ ). Aber für einen großen Teil zeigt die Serie, daß es sich hier um atypische Herdbildungen handelt. Für deren Illustration habe ich aus einer Serie 5 Schnitte beigegeben (Abb. $21 \mathrm{a}-\mathrm{C}$ ). Die Photogramme lassen hier nebeneinander gewöhnliche Knötchenherde und ,strauchartige Gliawucherungen erkennen; sie zeigen den Unterschied im Bau der typischen und atypischen Herde. Man sieht das Kommen und Gehen der gewöhnlichen Herde wie des ,Gliastrauchwerkes". Auch letzteres hebt sich aus der im großen und ganzen gesund erscheinenden Umgebung heraus; es ist ziemlich gut umschrieben, wenn auch die Grenzen etwas unbestimmter sind als bei den Knötchen, bei denen ja aber auch die nähere Umgebung (vgl. Abb. 11) von locker gestellten, pathologisch gewucherten Zellen durchsetzt sein kann. Bei den als ,,gliöses Strauchwerk" bezeichneten atypischen Herden kommt es nirgends zur Knötchenbildung, sondern diese atypischen Herde bleiben als lockere symplasmatische Verbände in ihrer ganzen Ausdehnung bestehen. Auch sie kann man durchschnittlich über 5-7 Schnitte verfolgen, das heißt, auch sie betragen in ihrem größten Durchmesser etwa $0,1 \mathrm{~mm}$. Nicht selten aber erstrecken sie sich nur über 3-4 Schnitte.

Dieses gliöse Strauchwerk habe ich, wie gesagt, in einem Falle in besonders auffälliger Form gefunden. Doch waren auch in vier anderen Fällen, bei denen ich das Kleinhirn durchgesehen habe, umschriebene Gliaverbände dieser Art in der Molekularschicht nachzuweisen. Sie waren nicht so reichlich; auch sie erstreckten sich über etwa 5 Schnitte. 
Die dritte Herdform, bei welcher es nicht zur Ausbildung des Knötchens kommt, ist der Gliastern. Oft bestehen diese Sterne oder Ringe nur in einer einfachen oder doppelten Schicht gliöser Zellen um ein präcapillares Gefäß. Es legt sich diese Schicht wie eine Schale um den Adventitialraum, resp. sie sitzt der gliösen Grenzmembran unmittelbar auf. Manchmal sind die Gliazellen um das Gefäß mehr strahlig angeordnet, so daß sie wie ein verkleinerter Rosettenherd erscheinen; sie stimmen zu den Bildern, welche die Nisslsche Schule als ,Gliastern" zu bezeichnen pflegt. Solche Gliasterne und gliösen Zellringe um die Gefäße kann man meist nur über 1-2 Schnitte verfolgen. Ich habe sie am häufigsten in der Brücke und im Rückenmark gesehen.

Das Ergebnis der Prüfung von Serienschnitten ist also, daß sich die ty pischen Knötchen durchschnittlich über eine Strecke von etwa 0,1 oder $0,12 \mathrm{~mm}$ ausdehnen, selten weiter; häufiger daß sie nur etwa die Hälf te dieses Durchmessers erreichen. Außerdem gibt es andere, herdförmige Bildungen, die nicht die Knötchenform haben, sondern die wir als atypische bezeichnen, nämlich „Rosettenherde“, Gliasterne und Gliazellringe um Gefäße, und vor allem das sehr aufällige ,Gliastrauchwerk"; letzteres ganz überwiegend in der Molekularzone des Kleinhirns. -

Am wichtigsten ist das Studium der Serienschnitte für die Bestimmung der histopathologischen Details.

\section{Histologische Einzelheiten.}

\section{Typische Herde.}

Beziehung der Herde zu Gefäßen. Meist schon am Einzelpräparat kann man bestätigen, was Fränkel zuerst dargelegt hat, daß die Herde sich um kleine Gefäße entwickeln. Aber bei dem Volumen, das die Knötchen durchschnittlich erreichen, ist es ja von vornherein klar, daß man nicht immer das Gefäß im Schnitt bekommt, und so bringen denn erst die Serien Sicherheit darüber, daß tatsächlich nie ein solcher Herd unabhängig von einem Gefäß sich etabliert; immer kann man ein „Herdgefäß" nachweisen. Mitunter gelingt es - bei Zufälligkeiten der Schnittrichting -, daß man das Gefäß in jedem folgenden Schnitt wieder findet und es von einem zum anderen Pol durch die ganze Ausdehnung des Herdes sehen kann. Ich verweise hier besonders auf die Bilder von dem Rosettenherd. Man sieht hier, daß das Herdchen mit dem Gefäße wandert. So verschiebt sich bei diesem Präparat die Zellanhäufung von der Gegend dicht unterhalb der Pia bis in die zweite Rindenschicht hinein, entsprechend dem Verlaufe dieses kleinen Rindengefäßes. Das Wandern der Herde illustriert auch die Kleinhirnserie (Herd $h$ und $\left.h^{1}\right)$.

Es sind im Zentralnervensystem immer nur kleine Gefäße, um weiche die Zellwucherung stattfindet, am häufigsten Präcapillaren und Capillaren Gern siedeln sich die Zellen um den Teilungswinkel eines kleinen Gefäßes an, so wie es das Mikrophotogramm 9 darstellt. Hier teilt sich das Gefäß in zwei Präcapillaren auf. Manchmal umgibt der Herd ein GefäB, wo es einen Zweig abgibt. Auch lagern sich die Zellen oft in den Bogen eines präcapillaren Gefäßes ein. Aber auch auf gerader Gefäßstrecke kann es zur Ausbildung der Herde kom- 
men. Ich verweise auf die Abb. 22. Hier umgibt der Zellknoten ziemlich gleichmäßig das Gefäß. Manche Capillaren stecken wie in einem Zellmuff. Auch nach der Teilungsstelle eines Gefäßes setzt sich nicht selten ein Knötchen an; hier viel häufiger unsymmetrisch. Bei den größeren Herden findet sich nicht nur ein „Herdgefäß ", sondern es sind - entsprechend der Vascularisation der grauen Substanz - oft mehrere Capillaren, welche das Gebiet des Herdes durchziehen. Man kann dann nicht sagen, daß dieses oder jenes das eigentliche „Herdgefäß“ ist. Denn es etabliert sich ja, wie wir schon sagten, ein Herd nicht gleichmäßig um ein Gefäßchen, sondern sehr häufig umwächst die Zellwucherung das Gefäß nur ganz unsymmetrisch, oder es sitzt gar der Herd einem Gefäß nur auf und wenige Zellen greifen um den anderen Teil des Schlauches herum. Wenn man den großen Herd aus der Brückenserie (Photogramm $19 \mathrm{a}-\mathrm{g}$ ) auf das Verhalten seiner Gefäße prüft, so sieht man in den ersten zwei Präparaten Capillaren, die vorwiegend in seinem peripherischen Abschnitt verlaufen und in den nächsten Schnitten nicht mehr zu finden sind; und in diesen nächsten Schnitten sind auch Gefäße, bzw. „ein Herdgefäß" nicht nachweisbar. Es scheint, daß solch ein Herd, wie man es auch in der Großhirnrinde hier und da sieht, an beiden Polen nur feinste Gefäße führt, daß also die Zellwucherung zwischen diese Capillarkomplexe eingeschaltet ist.

Das histologische Verhalten der „Herdgefäße“. Es ist selbstverständlich, daß bei den kompakten Knötchenherden die Prüfung auf die einzelnen Gefäßwandbestandteile oft überaus erschwert und mitunter unmöglich gemacht wird, da eben die Zellwucherung die Gefäßwandelemente überlagern kann, und auch der Serienprüfung stellen sich nicht selten erhebliche Schwierigkeiten entgegen, welche man von vornherein kaum erwarten sollte. Wer häufiger eine histopathologische Vergleichung an Serien vorgenommen hat, weiß, wie schwer es ist, im unmittelbar folgenden Schnitt die vorher gefundenen Gewebsbestandteile wiederzufinden, respektive sie miteinander so zu vereinigen, daß man sich etwa das Bild eines feinen Gefäßrohres zu rekonstruieren vermag. Dazu kommt, daß es sich eben nicht immer nur um ein einziges Herdgefäß handelt, sondern, wie erwähnt, in manchen Fällen mehrere Capillaren und Präcapillaren Teile des Gebietes durchziehen. Aber auch in solchen Fällen ebenso wie dort, wo wir es mit einem Gefäß zu tun haben, gelingt es natürlich nicht selten, sich ein klares Bild über das histologische Verhalten der zentralen Gefäße in dem Herde zu machen. Diese Bilder sind sehr verschieden. Wenn man ein Gefäß, wie es Abb. 22 zeigt, auf der Serie verfolgt, so läßt sich daran sicher beweisen, daß die Gefäßwandelemente keine erkennbare Veränderung erlitten haben. Das Gefäß, welches in der wiedergegebenen Abbildung in der einen Hälfte des Herdes von den Herdelementen überlagert ist, wird im folgenden Schnitt in seiner weiteren Strecke wieder gut analysierbar. Und so geht es vielfach. Das Ni s sl - Präparat deckt an diesem Gefäßchen, ebenso wie an capillären und präcapillären Gefäßen anderer Herde keinerlei Veränderungen an den Endothelien und den anderen Zellelementen auf. Eine Ergänzung findet das Methylenblaubild durch den Vergleich mit van Gieson-Präparaten und besonders mit der Elastica und der Tanninsilberfärbung. Wir sehen die feine Elastica des Gefäßchens und wo es sich um eine Capillare handelt, den feinen elastischen Saum erhalten. Wo die Imprägnation des mesench y malen Gefäßapparates gelingt, erscheinen auch diese Strukturen in den Herden unverändert. Gerade für die Verfolgung dieser Gewebsbestandteile erwiesen sich Serienpräparate, die nach der Klarfeldschen Modifikation der Achúcarroschen Tanninsilbermethode gefärbt waren, beson. ders instruktiv. Auch die von Alzheimer verwandte Mannsche MethylenblauEosinfärbung liefert gute Bilder, an denen man bei der eigenartigen Färbung, die das Gliazellprotoplasma hier annimmt, das Gefäßrohr durch den Gliaherd 
hindurch gut verfolgen kann. Endlich zeigen im Fettpräparat die Gefäßelemente im Herde in der Mehrzahl keine lipoiden Stoffe (s. u.).

Selbstverständlich ist an den kleinen Herden die histologische Analyse der Gefäße im Herd sehr viel einfacher, Einmal handelt es sich hier um ein Herdgefäß, und man braucht deshalb nicht mehrere Gefäßschläuche in ihrem mehr oder weniger langen Verlauf durch den Herd zu verfolgen. Dann ab $r$ ist vor allen Dingen der Zellgehalt leichter zu entwirren. Das Gefäßrohr ist nicht daria versteckt. So kann man sich an den beiden Schnitten durch einen Herd, wie er in $A b b .25 a$ u. $b$ wiedergegeben ist, gut überzeugen: daß hier die Wand des Gefäßes mit ihren Elementen intakt ist.

Im Gegensatz zu dieser Gruppe von Befunden gibt es eine andere, wo die Herdgefäße Veränderungen aufweisen. Betrachtet man zum Beispiel das Gefä $B$, dessen Teilungsstelle in Mikrophotogramm 9 wiedergegeben ist, in scinem Verlaufe durch den Herd mit stärkeren Systemen, so sieht man bald die eine, bald die andere Intimazelle auffallend blaß; es fehlt das feinere Chromatingerüst; die kernkörperchenartigen Bildungen sind nicht nachzuweisen; an manchen Endothelien erscheinen die Kerne leicht krümelig. Allermeist sind diese Veränderungen auf die Intimazellen beschränkt. An anderen Gefäßwandzellen habe ich gröbere regressive Veränderungen nicht sicher nachweisen können; zum Teil hängt das wohl auch mit dem Umstande zusammen, daß es im Zentralorgan allermeist Capillaren und Präcapillaren sind, um die sich ein Herd bildet. Während manche Endothelien nur diese degenerativen Unwandlungen der Kerne erkennen lassen, ist an anderen der Zelleib gequollen. Außer am Nis slschen Zellpräparat habe ich das vielfach bei Tanninsilberfärbung gefunden. An solchen Präparaten zeigte sich auch deutlich, daß die Veränderungen nicht immer nur die Intimazellen des Gefäßes betreffen, sondern daß auch die mesenchymalen Strukturen der Gefäße in den Fleckfieberherden leiden können. Im Gegensatz zu den vorhin erwähnten Bildern, wo man gerade an Serienschnitten, die nach der AchúcarroKlarfeldschen Methode gefärbt sind, sehr schön das Herdgefäß evtl. mit seinen Teilungen verfolgen und rekonstruieren kann und wo man es normal findet, erscheinen in anderen Fällen die mesenchymalen ,Netze" im Bereiche der erkrankten Partien des Herdgefäßes wie ausgelöscht. Z. B. so, daß das Gefäß im Teilungswinkel mit den angrenzenden Partien seiner Schenkel keine mesenchymalen Fasern und Lamellen fübrt und diese erst gegen die Peripherie des Herdes zu wieder in die Erscheinung treten. Dort, wo das mesenchymale Netz nicht imprägniert beziehungsweise geschwunden ist, erscheint auch das Endothel gequollen. Dabei ließ sich im Mikrophotogramm ein interessanter Befund erheben: während man nämlich im Tanninsilberpräparat selbst lediglich das Fehlen der merenchymalen Faserung und die Schwellung dea Endothels bemerkte, zeigte die photographische Platte in diesem veränderten Gefäßbereiche feingittrige und faserige Strukturen. Ich meine, daß es sich hier um Fibrinniederschläge handelt, denn diese Bilder des Mikrophotogramms passen gut zu dem, was man hier und da bei der Fibrinfärbung sieht. Ich habe ein solches Bild in Abb. 10 wiedergegeben. Hier ist das GefäBrohr selbst und auch der peripherische Teil des Lumens ebenso wie die das Gefäß unmittelbar umgebende Zone des Herdes von feinen Fibrinfäden und Gittern durchzogen. - Zu diesen Befunden stimmt oft das Verbalten des Gefäßrohres im Elasticapräparat; die Elastica ist hier nicht oder nur sehr matt gefärbt. Doch ist im allgemeinen die elastische Lamelle auch an Gefäßen mit Endothelschwellung und mäßigen regressiven Veränderungen der Zellen scharf und gut gefärbt.

Grobe nekrotische Zerstörungen der Gefäßwand fand ich nicht. Progressive Wucherungen von Intima-oder Adventitiazellen habe ich ebenfalls nicht sicher nachweisen können, und zwar weder im Zellpräparat noch bei der 
Tanninsilberfärbung. Auch an den Herden, in denen die Gefäßwand degenerativ verändert ist, fehlten alle Wucherungen etwa von der Art der Fibroblasten. bildung, und auch Proliferationen mesenchymaler Faserung sah ich niemals.

Die Fettpräparate lassen keine Verfettungen der Gefäßwandelemente erkennen. Es erscheint vielmehr bemerkenswert, daß die Gefäßwände im Herde selbst so gut wie frei von lipoiden Stoffen sind; während außerhalb des Herdes das betreffende Gefäß wie auch die Gefäße der Nachbarschaft in ihren Elementen lipoide Substanzen führen.

Die Gefäßscheide erweist sich sowohl in den Herden mit intakten Blutgefäßen wie in den anderen, welche regressive Umwandlungen erkennen lassen, fast durchgehends frei von infiltrierenden Elementen. Nur hier und da findet man einmal eine lymphocytäre Zelle oder auch einen Leukocyten im Adventitialraum. Sehr selten, daß man einmal mehrere weiße Blutelemente in der Scheide des Herdgefäßes sieht. Dagegen gehört es, wie ich schon bei der Besprechung des Übersichtsbildes erwähnte, geradezu zur Regel, daß dieses Gefäß oder sein Stamm außerhalb des Herdes ziemlich reichlich Infiltratzellen führt. Und zwar sind es ganz überwiegend Plasmazellen, besonders junge und kleine polyedrische Formen, in viel geringerer Zahl andere lymphocytäre Elemente und nur hier und da einmal verstreut ein Leukocyt. Die weitaus überwiegende Masse der Zellen sind eben Plasmazellen. Dort, wo sie då Gefäß außerhalb des Herdes besonders dicht infiltrieren, liegen sie in der gewöhnlichen Form epithelartig aneinander abgeplattet. Sie bleiben außerhalb des Herdes auf den adventitiellen Raum beschränkt. (Bezüglich der vereinzelten freien Plasmazellen im Herd selbst s. u.)

Zellige Zusammensetzung der Herde: Die Elemente, welche den Herd aufbauen, sind ganz überwiegend Gli a zellen. Die Abbildungen illustrieren das. Ein so durchsichtiger Herd, wie er in den beiden Abb. 25 a u. b abgebildet ist, läßt keinen Zweifel daran, daß hier alle Zellen gliöser Natur sind, und auch Abb. 22 dürfte das lehren. Die verschiedenen Gliaelemente sehen bei den Knötchenherden einander sehr ähnlich, zumal in der Hauptmasse des Herdes.

Die Einzelelemente sind nicht scharf voneinander abgegrenzt. Vielfach lassen sich deutliche plasmatische Verbindungen zwischen ihnen feststellen. Mitunter kann man geradezu von einem Symplasma sprechen, in das Kerne eingelagert sind; doch sind vielfach auch die Zellindividuen leidlich abgrenzbar. Die Kerne sind rund, klein und ziemlich chromatinreich; das Plasma ist im Nisslpräparat meist gut gefärbt. Es erscheint oft etwas krümelig und schmutzig trübe. Wo die Zellen dicht liegen, kann man natürlich Fortsätze der Gliaelemente nicht wohl erkennen. Erst gegen die Peripherie und dort, wo ein Herd ein lockereres Gefüge hat, werden die plasmatischen Verbände deutlicher. In der Außenzone stellen sich die Fortsätze gerne mehr oder weniger senkrecht zum Herd, und die Zellen erscheinen weithin ausgezogen, wie das die Abb. 11 zeigt. Es gibt sehr viele solche Herde, bei denen die Gliazellen - ähnlich wie sie beim Rosettenherd dem Gefäß unmittelbar aufsitzen - von der Peripherie des Herdes wegstreben. Die Gliazellen haben dann auch hier die Gestalt von Nis sIschen Stäbchen - und Wurstzellen (Abb. 31). Massenhaft sieht man sie zum Beispiel an dem Mikrophotogramm 11. Im Gegensatz zu solchen Herden, wo die Stäbchenzellbildung in der Peripherie sehr ausgesprochen und dadurch die Grenze des Knötchens gegen die Umgebung unscharf ist, legen sich bei anderen Herden die äußeren gliösen Elemente mit ihren ausgezogenen plasmatischen Fortsätzen mehr bogen- und schalenförmig übereinander und grenzen so den Herd schärfer ab.

Sehr reichlich sind Mitosen an den Gliazellen. Wie immer findet man natürlich die Monasterform am häufigsten. Aber auch den Diaster sieht man hier und da und auch pluripolare Mitosen kommen vor. (In den beigegebenen Abbildungen 
sind Kernteilungsfiguren an den Gliazellen mehrfach wiedergegeben.) Auch direkten Abschnürungsfiguren begegnet man, aber viel seltener als den Karyokinesen.

Die Anweridung der Alzheimerschen Methoden bringt zunächst als wichtigstes Ergebnis das mehr negative Resultat, daß die Gliaelemente der Herde keinerlei Eigentümlichkeiten der sogenannten a möboiden Glia besitzen und daß diese auch keine Granula etwa in der Form der Methylblaugranula usw. führen. Auch in den Alzheimerschen Präparaten sieht das Plasma der Gliazellen in den kompakten Herden etwas krümelig und bröckelig aus. Oft kann man, wo die Zellen weniger dicht gelagert sind, erkennen, wie die Zelle mit ihrer äußeren Plasmamasse und den davon ausgehenden Fortsätzen die noch persistierenden Nervenfasern umfließt.

Die Untersuchung nach der Weigertschen Gliafasermethode ergibt ebenfalls vor allem ein negatives Resultat, nämlich das Fehlen jeder Gliafaserwucherung. Maßgebend für die Beurteilung sind hier natürlich nicht die Bilder von der gliafaserfreien bzw. -armen Rinde wie vielmehr die Befunde in solchen Gegenden, wo normaliter ein reichliches Gliafaserlager besteht, also etwa im Hirnstamm und im Rückenmark: Die den Herd zusammensetzenden Gliazellen zeigen keine Gliafaserneubild ung (Abb. 13). Und auch in der Umgebung besteht an den Gliazellen nicht die Neigung, mit einer Faserbildung zu reagieren.

Bei den Fettfärbungen ist das gewöhnliche Bild so, wie es Abb. 34 wiedergibt. Die Gliazellen führen demnach feine lipoide Tröpfchen in ihrem Zelleib und auch in ihren Fortsätzen. Aber die lipoiden Stoffe sind durchschnittlich nur gering an Masse und die Einlagerung in die Zellen eben nur recht mäßig. Sehr selten ist ein Bild, wie es Abb. 35 zeigt, wo in einem sehr großen Herd der Rinde die zu Fett abgebauten Substanzen überaus reichlich sind und wo auch die gliösen Elemente die Neigung zur Abrundung zu Körnchenkugeln haben - ein ungewöhnliches Verhalten, das mit einer ungewöhnlich starken regressiven Veränderung am Herdgefäß in Zusammenhang steht (s. u.).

Im Zellpräparat sieht man hier ganz ausnahmsweise gliöse Gitterzellen, wie das ja nach dem Befunde im Fettpräparat nicht anders zu erwarten ist. Sonst spielen Gitterzellen beim Fleckfieber keine Rolle. Sie gehören nicht zu dem gewöhnlichen histologischen Bilde der Herde. Nur a usnahmsweise stellen sie sich, wie in dem erwähnten Bilde, einmal in mäßiger Anzahl dar. Sehr selten und sehr spärlich findet man sie wohl auch bei größeren Herden im Bereiche des Ein- oder Austrittes des Herdgefäßes. -

An der Zusammensetzung der Herde beteiligen sich natürlich mehr oder weniger noch die an Ort und Stelle befindlichen Gewebsbestandteile, wie die Ganglienzellen, die Nervenfasern und die Neuroglia. An einer ganzen Reihe der Abbildungen bemerkt man im Herde selbst, besonders in seiner Peripherio, Ganglienzellen. Viele dieser Elemente weisen, auch wenn sie von der Herdmasse dicht umschlossen sind, keine gröberen Veränderungen auf, insbesondere erscheint ihr Kern vielfach nahezu normal. Nur die Nisslschen Körperchen sind unscharf, vielfach geschwunden, stellenweise verklumpt; die ungefärbten Bahnen sind verwaschen. Solche nur geringfügige Veränderungen sieht man auch an den Ganglienzellen, die von den Herdelementen in ihrer Konfiguration beeinflußt werden und wie eingebuchtet oder umgebogen erscheinen. Andere Nervenzellen sind dagegen auf das schwerste verändert. Die Nis slsche Substanz ist ganz aufgelöst und nur noch Krümel der Granula sind nachweisbar. Oder man sieht einige wabig veränderte Zelleibsteile, während die Zellgrenzen ganz verwischt und Teile des Zelleibes zugrunde gegangen sind. Manche Bilder sind wohl als Verflüssigungsvorgänge aufzufassen. Der Kern ist hier meistens in der Weise verändert, daß die Kapsel aufgelöst und das Kernchromatin in feinsten Stäubchen 
weithin über den basalen Teil der Zelle verstreut ist. Die Vorgänge führen zum völligen Untergang der Nervenzellen, zumal in der zentralen Hauptmasse des Herdes. Den Untergang der Zellen beziehungsweise ihren Ausfall erkennt man ja ohne weiteres daran, daß eben die Ganglienzellen, wo sie entsprechend den lokalen Verhältnissen (in denen sich der Herd entwickelt) vorhanden sein müßten, tatsächlich fehlen.

In der Peripherie der Herde umschließen die Fortsätze der Gliazellen mit ihren Zweigen die Nervenfasern und verstärken das gliöse Maschenwerk um die Fasern. An locker gebauten Herden ist das zumal im Mark besonders gut zu sehen. Präparate, die nach der Alzheimer-Mannschen Färbung hergestellt sind, zeigen an den Grenzen der Herde, auch in der Rinde derbe dicke Gliaringe; oft sieht das gliöse Protoplasma wie durchlöchert aus; das heißt, es schiebt sich eben die plasmatische Substanz der Gliaelemente an den Nervenfasern vorbei und umgibt sie mit einer breiten Plasmaschicht. Die Nervenfasern, soweit sie noch nachweisbar sind, sind vielfach gequollen und nehmen bei dieser Färbung eine bläuliche oder blaurötliche Färbung an. Ähnlich sind die Bilder im Bielsch ow s k y Präparat. - Auch die Nervenfasern gehen in dem Hauptteil des Herdes zugrunde. Die Vorgänge bei ihrem Zerfall sind verhältnismäßig schwer zu analysieren. Ich gehe hier nicht darauf ein. In ausgebildeten kompakten Herden erscheint die Markfasermasse im Bereiche des Herdes ausgefallen und in seiner Peripherie gelichtet, so wie es das Photogramm 14 darstellt. Das Bielschow s k vsche Achsenzylinderbild stimmt damit überein; der Achsenzylindergehalt ist hier nicht wesentlich größer als es dem Markscheidenbilde entspricht.

Von den Gliafasern wurde vorhin schon gesagt, daß sie im Bereiche des Herdes nicht die Neigung haben, zu proliferieren. An den Herden selbst sieht man im wesentlichen zwei verschiedenartige Bilder. Erstens solche Herde, an welchen das Gliafaserwerk keine Anderung auch im Herde aufweist. Das sind die locker gebauten Knötchen; wohl auch solche, die noch verhältnismäßig jungen Datums sind. Von diesem Bilde gibt es allerhand Übergänge zu der zweiten häufigeren Form, wo - ebenso wie die anderen ektodermalen Bestandteile - auch die Gliafaserzüge, die normalerweise an Ort und Stelle vorhanden sind, im Bereich des Herdes aufgelöst und geschwunden sind (Abb. 13).

Abgesehen von den eindeutig als Gliazellen zu diagnostizierenden Herdelementen und von den eben erwähnten mehr oder weniger großen Resten der lokalen Gewebsbestandteile gibt es andere Elemente, die ihrer Natur nach nicht exakt zu bestimmen sind. Es sind das vor allem solche Zellen, bei denen man auch im Nisslpräparat keinen deutlichen Plasmaleib feststellen oder nur spärlichste Andeutungen davon wahrnehmen kann; Elemente, die auch durch ihre merkwürdig gestalteten Kerne auffallen. Diese sind ziemlich blaß mit unregelmäßig verteilten Chronatinpunkten; sie sind oft rechteckig gestaltet, dann wieder wetzsteinförmig, oder sie erscheinen in einer Hälfte oder einem Teil der Kernmasse scharf umgebogen, nahezu rechtwinklig abgeknickt oder auch hakenförmig. Auffallend erscheint immer bei diesen Kernen ihre eckige scharfkantige Form. Was das für Elemente sind, weiß ich nicht zu sagen. Man kennt sie ja auch von allerhand anderen Prozessen her, bei denen - um dies hervorzuheben - mesodermale Wucherungen nicht bestehen und die Grenzen zwischen Ektoderm und Mesoderm nicht zerstört sind. Das Nächstliegende wäre, anzunehmen, daß es Gliazellen sind, und bei der außerordentlichen Vielgestaltigkeit, die wir an den gliösen Elementen kennengelernt haben, erscheint dies heute nicht ausgeschlossen.

Beteiligung von Blutzellen an der Zusammensetzung der Herde. Rote Blutkörperchen fehlen in den Herden bei meinen Fällen. Ich habe sie nur hier und da in der Adventitialscheide der Herdgefäße, ebenso wie außerhalb der 
Herde an den zentralen Gefäßen sonst gesehen. Ringblutungen, wie sie Herzog beschrieben hat, waren in meinem Material nicht zu finden; sie sind auch nach Herzogs Darstellung offenbar selten und gehören nicht eigentlich zum Bild des Fleckfiebers; sie kommen wohl nur bei besonders schwerem Krankheitsverlauf und bei stärkerer Erkrankung der Gefäßwand zur Beobachtung.

Sehr oft sind den Herdelementen Leukocyten und lymphocytäre Ele me n te beigemischt. Von der Häufigkeit und der Bedeutung ihres Vorkommens in den Herden wird nachher die Rede sein. Hier sei nur auf die häufigsten Bilder hingewiesen, unter denen sich die Beteiligung weißer Blutzellen an der Zusammensetzung der Herde darzustellen pflegt. Beispiele dafür habe ich in den Abbildungen gegeben. Abb. 26 zeigt in einem ganz jungen Herde reichliche Mengen von Le u kocyten zwischen den noch locker angeordneten und in frischer progressiver Umwandlung begriffenen Gliaelementen. Leukocyten sind auch noch außerlalb des eigentlichen Herdes im zentralen Gewebe verstreut. Derartige frische le ukoc ytenhaltige Herde habe ich in alle $n$ meinen Fällen gefunden, aber in a u Ber ordentlich verschiedener Häufigkeit. In manchem Falle mußte man lange danach suchen, in anderen begegnete man ihnen recht oft. Ähnlich steht es mit dem zweiten Bilde, das ich hier als nicht seltenen Befund im Photogramm 12 wiedergegeben habe: zahlreiche Leukocyten sind in einem schon voll ausgebildeten Herd verstreut. Lymphocytäre Elemente können in solchen Herden fehlen, finden sich aber auch neben Leukocyten in sehr verschiedener Anzahl. Besonders oft stellen sich die lymphocytenhaltigen Herde so dar, wie es die Abb. 27 illustriert. Hier haben wir es mit einem voll ausgebildeten und zum Teil regressiv umgewandelten Herd zu tun. In solchen Herden durchsetzen die weißen Blutelemente vorwiegend die zentralen, weniger die peripherischen Zonen des Herdes; gesenüber den Gliazellen bleiben sie in geringfügiger Zahl. Oft sind daneben Leukocyten in ganz spärlichen Exemplaren vorhanden. Unter den lymphocytären Elementen sind vereinzelte gewöhnliche Lymphocyten, dann auch ebenfalls nur vereinzelt große Mononucleäre und endlich etwas zahlreicher Plasmazellen in sehr verschiedenen Formen. Letztere haben nur selten alle ihre Charakteristica, meist sind sie in Degeneration begriffen: die Kernkapsel erscheint vorgebuckelt, als wenn das Kernchromatin sie nach außen triebe, so daß der Kern höckrig aussieht; das Plasma erscheint an manchen von diesen Zellen durch einen breiten hellen Hof vom Kerne getrennt. An manchen Elementen wird der außen tief blauschwarz gefärbte Kern runzlig. Von den pyknotischen Formen ist es natürlich schwer zu entscheiden, ob sie regressiv veränderten Plasmazellen angehören, oder ob sie von entarteten Gliazellen herstammen. Man kann Übergänge sowohl zwischen der einen wie zwischen der anderen Zellart und ihren Degenerationsformen beobachten. Auch die Leukocyten weisen oft Zerfallserscheinungen auf. Besonders in einem meiner Fälle sah ich in den Herden merkwürdige, oft feinkugelige Kernfragmente. Makrophagen fand ich in den Herden nicht.

\section{Atypische Herde.}

Bei der Besprechung der Serienbilder sahen wir, daß die Rosettenherde vorwiegend in der obersten Großhirnrinde und wesentlich seltener in der Molekularzone des Kleinhirns vorkommen und daß das ,gliöse Strauch. werk" fast ausschließlich an die Molekularzone der Kleinhirnrinde gebunden ist und nur Andeutungen davon in der ersten Schicht der Großhirnrinde vorhanden sind. Es ließ sich außerdem schon im Übersichtsbild an den Serienschnitten im allgemeinen nachweisen, daß wie die typischen Knötchen, so auch diese atypischen Herde sich um ein Gefä $\beta$ etablieren. Für die Rosetten ist das immer leicht zu erweisen. Für das Strauchwerk liegen die Dinge deshalb anders, weil es ja im allgemeinen einen etwas größeren Raum einnimmt als ein typisches 
Knötchen, und da sind natürlich immer mehrere Gefäßchen in seinem Bezirke, weil ja die graue Oberflächenzone des Kleinhirns stark vascularisiert ist. Aber wir hatten schon bei den Knötchenherden vielfach gesehen, daß man keineswegs immer dieses oder jenes Gefäß als das Herdgefäß ansprechen kann; denn bei etwas größeren typischen Herden (die sich über elne Anzahl von 6-8 Schnitten erstrecken) findet man ja fast immer auch mehrere Gefäßchen, die den Herd oder Teile desselben durchziehen. - Ist das Strauchwerk nur schmal, so ist die Beziehung zu einem Gefäß deutlich zu erkennen; meist sind die ausgedehnten, senkrecht gestellten Gliabüsche regelmäßig von einer ganzen Anzahl von Gefäßchen durchzogen. Bei den (hier nicht wiedergegebenen) Streifen, welche vielfach schräg die Molekularzone durchziehen oder in der Tiefe einer Kleinhirnfurche die oberste Rinde durchqueren. erkennt man ebenfalls die Beziehungen zur Gefäßanordnung; hier ist es häufig so, daß eine Präcapillare einen Seitenzweig abschickt oder daß die plasmatische Gliawucherung um einen weiten Gefäßbogen und den schräg aufsteigenden Ast etabliert ist.

Viel einfacher und klarer als an den typischen und mehr oder weniger kompakten Knötchen ist bei dem lockeren Strauchwerk zu beweisen, daß die Gefäßchen hier intakt sind. Ich habe ni mals Veränderungen daran nachweisen können, und zwar mit keiner dafür in Betracht kommenden Methode.

Auch mit dem Infiltrat ist es wie mit den typischen Herden, daß in diesen plasmatischen Gliabüschen die durchziehenden Gefäße im allgemeinen keine lymphocytären Elemente in ihren Scheiden beherbergen. Erst außerhalb dieser atypischen Herde führen die Gefäße Plasmazellen in der Adventitia.

Bezüglich der feineren histologischen Eigenschaften der atypischen Herde kann ich auf die Illustrationen verweisen. Die beiden Mikrophotogramme $15 \mathrm{u} .16$ geben eine Ergänzung zu dem, was die Serienbilder zeigten, und illustrieren die Anlage und Gestalt des plasmatischen Gliastrauchwerkes und seine Abgrenzung gegen die Umgebung. Die beiden Zeichnungen Abb. 28 u. 29 veranschaulichen den Bau und die Verästelung der gliösen Elemente. Wie bei den Rosetten in der Großhirnrinde die Gliazellen fast ausschließlich die Stäbchen- oder Wurstform haben, also langgestreckte, teils gerade, teils gebogene Elemente mit weithinreichenden polständigen ziemlich breiten Fortsätzen sind, so sind auch im Strauchwerk der obersten Kleinhirnrinde die Zellen vielfach lang ausgezogen und stellen sich senkrecht zur Rinde, entsprechend der normalen Anordnung der Berg man nschen Gliazellen. Schräg und quer dazwischen sind verbindende Gliazellen gelagert; außer stäbchenartigen Elementen sieht man mehr runde oder ovale gliöse Zellen mit feinen strahligen Fortsätzen. Die Gliazelleiber wie ihre Fortsätze werden durch die $\mathrm{Ni}$ is slschen Stippchen färberisch gut herausgehoben. In besonders breiten Gliabalken ist die chromophile Substanz peripher angeordnet, und wo solche Balken sehr dick sind und ihre basophile Substanz die Außenzone durchsetzt, sehen sie auf dem Querschnitt und wo sie der Länge nach angeschnitten sind, wie Schläuche aus.

Ganz außerordentlich oft findet man hier Mitosen (vgl. besonders Abb. 28). Neben dem gewöhnlichen Monasterbild beobachtet man auch hier und da andere Phasen der Karyokinese und atypische (oder vielleicht pluripolare) Kernteilungs. figuren. In manchen Elementen sieht man mitten in der Phase der Karyokinese bereits regressive Zerfallserscheinungen an den Chromatinschleifen und Versprengung der Chromosomen.

Im allgemeinen imponiert dieses Strauchwerk als eine zusa m menhängende Masse, da die einzelnen Gliazellen breite plasmatische Verbindungen miteinander eingehen. Aber außer dem syncytialen Verband bemerkt man auch bloße Überkreuzungen der gliösen Plasmabalken. 
Charakteristisch für die Rosetten wie für das Gliastrauchwerk ist die frühzeitige Neigung zu regressiver Umwandlung der Zellen und auch deren spezielle Art. Abb. 28 zeigt einige solcher Exemplare, die mitten zwischen den anderen noch in progressiver Metamorphose befindlichen Gliazellen bereits eine starke Schmalheit und Schrumpfung des Kernes un eine Schlängelung der verschmälerten Plasmafortsätze aufweisen. Im Fettpräparat führen diese regressiven Elemente im Zelleib und in den verschmälerten plasmatischen Brücken lipoide Stoffe, so daß sich die Plasmazïge solcher Gliazellen herausheben. Ganz ähnlich ist der Befund an den Zellen der Großhirnrosetten. Vielleicht noch rascher erleidet hier der Kern eine regressive Metamorphose, die frühzeitig zur Pyknose führt, und die plasmatischen Fortsätze schrumpfen zu derben Spangen und knorrigen Gebilden, die verstreut Fettíröpfehen enthalten.

\section{Diffuse Veränderungen.}

Veränderungen des zentralen Gewebes. Von den Ganglienzellen der Herde war bereits bei der Besprechung der Knötchen bemerkt worden, daß sie, wenigstens in deren Peripherie, auffallend geringe Strukturanomalien bieten. Das gilt noch mehr für die Ganglienzellen sonst. Schwere Erkrankungsformen habe ich in meinen Fällen rur scl n gesehen; im allgemeinen beschränken sich die Abweichungen vom normalen Bilde auf Verwaschensein der Nisslzeichnung; die Granula sind an Volumen reduziert, ziemlich blaß, die ganze Zelle feinstreifig, die sogenannten ungefärbten Bahnen verschwommen. Grobe Kerndestruktionen fand ich nirgends. Hier und da sieht man in dem einen Falle etwas mehr als in dem anderen das Bild der sogenannten chronischen Ganglienzellerkiankung zumal an den Pyramiden der dritten Schicht; es sind dabei immer nur einzelne Exemplare von dieser Krankheitsform ergriffen. Ihr Vorkommen beim Fleckfieber beweist wieder nur das, was $\mathrm{N}$ is $\leqslant 1$ schon lange betont hat, daß nämlich diese sogenannte chronische Veränderung keineswegs nur bei chronischen Prozessen vorkommt, sondern daß sich das so bezeichnete Bild auch rasch bei akuten Erkrankungen entwickeln kann. Mit dem Namen ,chronische Zellerkrankung" darf man also nicht auch den Begriff eines chronischen Prozesses an der Nervenzelle verbinden. - In dem einen oder anderen Fall tritt eine in Anbetracht des jugendlichen Alters der Individuen auffallend weitgehende Ansammlung von lipoiden Stoffen hervor - ein Befund, den wir ja ebenfalls bei schweren Allgemeinerkrankungen nicht selten erheben ( $\mathrm{R}$ anke).

Es sind also die Zellbilder beim Fleckfieber nicht charakteristisch oder auffällig, sie gleichen denen, wie wir sie häufig bei Infektionskrankheiten finden.

Das Markfaserbild bietet außerhalb der Herde keine Abweichungen von der Norm, insbesondere trifft man nicht auf Degenerationen in den langen Bahnen. Daß sich jedoch auch im Mark Zerfallsvorgänge abspielen, dafür spricht der Befund im Fettp äparat. In dem einen Fall mehr und im anderen weniger sind im Radius und auch im Marklager sonst, sowie im Markweiß des Hirnstammes und des Rückenmarks mit groben Fetttropfen beladene Transportelemente um die Gefäße. Abb. 36 zeigt solche mit lipoiden Massen angefüllte Gliazellen, die noch vor der gliösen Grenzmembran in der Glia perivaccularis liegen; andere mit Fett beladene Körnchenzellen sind im Adventitialraum verstreut. Ein Befund, wie er in dieser Zeichnung wiedergegeben ist, stellt schon eine verhältnismäßig starke Ansammlung von Fettkörnchenzellen an den Gefäßen dar. Vielfach sind die Zellen geringer an Zahl und auch weniger stark mit Fett beladen. - In der Rinde spricht der Befund im Fettpräparat ebenfalls für diffuse Zerfallsvorgänge; denn auch dort, wo keine Herde liegen oder wo sie nur spärlich sind, sieht man von den Adventitialzellen Fett röpfchen aufgenommen und die Gliazellen führen vielfach feinste Fetttrönfchen in allerdings nur geringem Grad. 
Im gleichen Sinne sprechen auch die diffusen Wucherungserscheinungen an der zelligen Neuroglia sowohl im Mark wie in der Rinde. Man trifft hier vielfach progressive Umwandlungen der Gliaelemente, die sich in einer Zunahme des Kernchromatins und vornehmlich in einer Vermehrung und deutlicheren Färbbarkeit des Plasmaleibes und seiner Fortsätze zeigen. Amöboide Typen habe ich nie gesehen. Häufig sind Zellen, wie sie in den Abb. 11 u. 23 a u Berhalb der Herde zu sehen sind: die Zusammenlagerung von zwei und drei Gliazellen, die eine große Zahl von zarten plasmatischen Fortsätzen aussenden. Solche Wucherungserscheinungen an der Glia sieht man auch in Rindengebieten, wo die Herdbildung sehr gering und ein Zusammenhang mit Herden ausgeschlossen ist. $\mathrm{Ab}$ und zu kommen durch die Verschmelzung einzelner Gliazellen kleine "Rasen“" in der Rinde zustande. Sehr oft nehmen die Gliazellen Stäbchenform an. Die Proliferation der Gliazellen zcigt sich auch in dem Volkommen von Mitosen in der Rinde wie im Hirnstamm und im Rückenmark an. Im Rückenmark tritt eine Verstärkung des gliösen Maschenwerkes der Stränge hervor. Sehr deutlich sind die diffusen Proliferationsvorgänge der Neuroglia auch in der Molekularzone des Kleinhirns, wo man schon am Übersichtsbild (siehe Mikrophotogramm 2l a) eine feine radiäre Streifung bemerkt, nämlich ein Breiterwerden der plasmatischen Fortsätze der Bergmannschen Gliazellen und eine stärkere Färbbarkeit derselben. Die Molekularzone erscheint dadurch fein radiär gestreift. Die Stäbchenform der Gliazellen ist nicht nur hier, sondern auch an herdfreien Stellen der Großhirnrinde sehr auffällig.

Gefäße. Der hervorstechendste Befund am Gefäßsystem sind die Infiltrationen. Von ihnen war sehon bei Besprechung des Übersichtsbildes die Rede und was dort über ihre Verteilung und ihre große regionäre Verschiedenheit gesagt war, wird später noch bei der Besprechung der Bedeutung dieses Befundes ergänzt werden. Ich beschränke mich deshalb jetzt darauf, zu erwähnen, daß die Plasmazellen weitaus die Mehrzahl der in die Adventitialräume eingelagerten Zellen darstellen und daß diese ebenso wie die anderen lymphocytären Elemente außerhalb der Herde auf die Adventitialscheide beschränkt bleiben. Sehr häufig sind die Plasmazellen klein, auch wenn sie bereits alle Merkmale dieser Zellart tragen; ihr Zelleib ist oft nur gering entwickelt und auch, wo sie dichter beieinander liegen, haben sie vielfach noch nicht die epithelartige Gestalt. Aber mitten zwischen diesen kleinen und oft noch rundlichen Plasmazellen sieht man große polyedrische Formen; und in manchen Fällen bzw. in manchen Gegenden tapezieren die Plasmazellen als große Elemente in epithelartiger Anordnung den Adventitialraum aus. - Das diffuse Infiltrat betrifft in der Rinde und den grauen Kernen vorwiegend die kleinen Arterien und die Präcapillaren und Capillaren, während etwas größere Gefäße frei erscheinen. Stellenweise aber sind gerade wieder solche Arterien and Venen von einem dichten Infiltrat umscheidet, wie das ja bereits das Übersichtsbild lehrte (Abb. 1 u. 5). An dem gleichen Gefäß ist die Einlagerung mit diesen Zellen oft eine Strecke weit gleichmäßig dicht, dann nur dürftig und vereinzelt. Wo die Infiltrationen spärlich sind, sieht man sie auch bei diesem Prozeß am häufigsten an den Teilungsstellen der Gefäße. Dem Plasmazellinfiltrat sind häufig gewöhnliche Lymphocyten in geringer Zahl beigemischt. Selten sieht man mal einen Leukocyten. Selten sind auch Makrophagen. Letztere sitzen ab und $\mathrm{zu}$ an den Teilungswinkeln von Rindengefäßen. Sie treten als infiltrierende Elemente hinter den lymphocytären Zellformen völlig zurück. Eine Ausnahme davon machen nur die Bilder in zweien meiner Fälle. In beiden waren zwar die Gefäße der Groß. und Kleinhirnrinde und auch des Hauptgebietes des Hirnstammes - wie gewöhnlich - im allgemeinen frei von solchen Zellen und wiesen nur das eben geschilderte lymphocytäre bzw. plasmacytäre Infiltrat auf. Aber in dem einen Falle, von dem die Mikrophotogramme 17 u. 18 stammen, waren die Scheiden der langen 
Markradiusgefäße von Makrophagen dicht besetzt. An manchen Gefäßen (Abb. 18) herrschten sie sogar ganz entschieden vor, während sie an anderen Gefäßen des Markradius mit Plasmazellen gemischt waren (Abb. 17). Die Gefäße des eigentlichen Marklagers dagegen waren wieder frei von solchen großen phagocytären Elementen. In dem anderen Falle zeigten die mittleren und größeren Venen und Arterien in den basalen Ganglien reichlich Makrophagen neben Plasmazellen - in ganz der gleichen Form, wie wir sie beim Fleckfieber in den Meningen treffen (s. u.).

Regressive Wandveränderungen habe ich an den zentralen Gefäßen außerhalb der Herde nirgends gefunden. Die verschiedenen hier in Betracht kommenden Methoden haben überall normale Verhältnisse ergeben. - Daß die Adventitialzellen vielfach und besonders in der Hirnrinde lipoide Substanzen führen, ist - wie bereits erwähnt wurde - auf den Abtransport lipoider Abbauprodukte in die adventitiellen Lymphräume zu beziehen und ist nicht als selbständiger degenerativer Krankheitsvorgang an den Gefäßwandelementen aufzufassen.

In einigen meiner Fälle waren Zeichen einer geringfügigen prog̀ressiven Metamorphose an den Intimazellen zu beobachten. Durchschnittlich freilich erscheinen die langgestreckten Zelleiber nur succulent, wie wir das bei schweren Allgemeinerkrankungen und bei allerhand stürmischen Prozessen am Zentralorgan gewissermaßen als Nebenerscheinung sehen. Aber hier und da zeigte sich doch außer der Schwellung des Plasmas eine recht intensive Färbung der Intimazellen und dadurch wie infolge der progressiven Umwandlung der plasmatischen Randglia erschienen vielfach die Capillaren und Präcapillaren doppelt gestreift. Auch die Kerne der Intimazellen wiesen stellenweise progressive Umwandlungen auf. Das war besonders in einem Fall mit sehr zahlreichen Großhirnrindenherden deutlich. Hier kam es an ganz vereinzelten Stellen zu einer wirklichen Vermehrung der Intimazellen, und zwar besonders an Teilungswinkeln im Bereiche der einen Hälfte des Gefäßrohres (Abb. 23), und zwar außerhalb der Herdbildung. Es muß jedoch betont werden, daß eine solche Zellvermehrung an der Gefäßintima nur in diesem einen Falle und nur vereinzelt gesehen wurde.

Im Gegensatz zu anderen Organen zeigt das Zentralnervensystem „hyaline“" Thromben, von denen in der Literatur des Fleckfiebers viel die Rede ist, nicht häufig. Ich babe sie nur in zweien meiner Fälle $a b$ und zu bemerkt. Sonst fiel an meinem Material immer die außerordentliche Blutfülle der Gefäße auf und auch das Vorkommen von zahlreichen großen mononucleären Formen neben anderen weißen Blutzellen im Lumen. Nicht selten fanden sich frische kleine Blutaustritte, meist nur im Adventitialraum, selten darüber hinaus. Eine Reaktion auf diese fand ich nirgends. Es sind offenbar unbedeutende agonale Blutaustritte.

Pia. Auch die Veränderungen an den makroskopisch getrübt erscheinenden weichen Häuten ließen sich bereits im großen und ganzen im Übersichtsbild erkennen, nämlich die mäßige Infiltration mit Plasmazellen und anderen lymphocytären Elementen und die starke Durchsetzung mit Makrophagen. Von der wechselnden Intensität dieser meningealen Zellmassen und ihrer Verteilung war bereits die Rede. An Zahl übertreffen die Makrophagen alle anderen eingelagerten Zellen. Unter letzteren stehen an erster Stelle die Plasmazellen. Sehr viel seltener sind gewöhnliche Lymphocyten. Vereinzelt kommen große mononucleäre Formen und mehrkernige Leukocyten vor. Auch mit Fett beladene Körnchenzellen von der Form echter Gitterzellen sieht man vereinzelt wie ja auch mal im Adventitialraum zentraler Gefäße. Der stürmische frische Prozeß gestattet es, hier allerhand junge Entwicklungsformen der Plasmazellen neben mitotischer Teilung dieser Elemente zu beobachten (s. S. 36). Die Makrophagen sind in der Abb. 32 illustriert. Sie haben die gewöhnliche ausgesprochen bläschenförmige Gestalt und zeichnen sich durch ihr ziemlich intensiv gefärbtes basophiles fein- 
gittriges Ektoplasma aus; der Kern ist im Verhältnis zur Größe des Zelleibes klein und an den Rand gedrängt. Sie führen im Zellinnern Zell- und Kernreste und allerhand zerfallende Massen. Die hier im Bild wiedergegebenen Elemente haben in ihrem Innern gelbes und grünes Blutpigment, Fragmente von roten Blutkörperchen, Leukocyten und Leukocytenkernen; auch Plasmazellen sind nicht selten von ihnen eingeschlossen. Vielfach haben die in ihnen liegenden zugrunde gehenden Zellen die Form der sogenannten „Vogelaugen“. Andere Makrophagen sind in ihrem Innern vakuolisiert; es scheint, daß die aufgenommenen Zerfallsmassen verflüssigt werden. Außer durch Neubildung aus seßhaften Meningealelementen (s. S. 37) vermehren sich diese phagocytären Zellen mitotisch und amitotisch. Oft entstehen bei direkter Kernteilung Abschnürungen größerer und kleiner Kernlappen und vielkernige Zellgebilde. Die Karyokinese findet auch an stark beladenen (z. B. Plasmazellen einschließenden) Elementen statt.

Aus den hier mitgeteilten Befunden beim Eleckfieber lassen sich zwei Reihen von grundsätzlich wichtigen Ergebnissen ableiten. Die einen gehen die spezielle Pathologie des Fleckfiebers selber an, die anderen haben ihre Wichtigkeit für die allgemeine Pathologie, insbesondere für die Rindenanatomie.

In der Pathologie des Fleckfiebers dürften diese Untersuchungen Wichtigkeit für die Frage der Pathogenese besitzen. Es war schon einleitend hervorgehoben worden, daß von den meisten Forschern die Herdbildung auf eine primäre Erkrankung der Gefäßwand zurückgeführt wird: die Gefäßwand erleide zunächst eine allgemeine oder häufiger eine umschriebene Nekrose ihrer Wand und es komme dann zu ęiner Wucherung der Gefäßwandzellen, die zusammen mit periadventitiellen Bindegewebszellen das Knötchen bilden. Es braucht nicht erst noch ausdrücklich bestätigt zu werden, daß tatsächlich beim Fleckfieber an den ausgebildeten Herden in den verschiedensten Organen vielfach deutlich regressive Gefäßwandveränderungen beobachtet werden, und auch in meinen Fällen zeigten die Bilder besonders von der Haut nicht selten fleckförmige Wanderkrankung der Herdgefäße. Was wir an den Herden des Zentralnervensystems sahen, habe ich vorhin beschrieben. Danach muß ich ausdrücklich hervorheben, daß ich solche Wandveränderungen, die man füglich ,Nekrosen“" nennen könnte, in den Herden des Gehirns nie gesehen habe. Doch waren in allen Fällen in einem Teile der Herde bald mehr, bald weniger regressive Umwandlungen, besonders an der Intima zu beobachten. Ich erinnere an die histologischen Verhältnisse, wie sie das Nisslpräparat dartut, und außerdem besonders an die Befunde im Tanninsilber-, Elastica- und Fibrinpräparat. Aber ich habe solche Gefäßwandveränderungen immer nur in einem Teile der a usgebildeten „,kompakten“ Herde gesehen.

Ich kann ihnen für die Pathogenese keine Rolle zusprechen und muß vielmehr die Anschaung ablehnen, wonach die herdförmige Wucherung eine Folgeerscheinung 
einer primären, mehr oder weniger umschriebenen Gefä $\beta$ wandnekrose ist. Denn entscheidend ist in dieser Frage natürlich nicht der positive Befund in einzelnen Herden, sondern der negative, d. h. der sichere Nachweis des Fehlens von Gefäßwanderkrankungen im Gros der Herde. Maßgebend in der Frage nach der pathogenetischen Wirksamkeit von Gefäßveränderungen muß der Befund an beginnenden Herden sein. Ich habe regelmäßig in allen Fällen auf ausgedehnten Serien junge Herde studiert und habe niemals trotz schon bestehender herdförmiger Gliawucherung eine Veränderung der Gefäßwände gefunden. Und auch in den meisten vollentwickelten Herden waren die Gefäße nicht nachweisbar verändert, weder im Tanninsilber-, noch im Elasticapräparat, noch im Zellbilde. Wie schon erwähnt, ist es schwierig, bei einem größeren Herd mit Sicherheit jedes Gefäß, das durch ihn hindurchzieht oder in seiner Peripherie verläuft, exakt zu verfolgen. Ebenso ist es ja oft so, daß der Herd sich von vornherein um eine größere Strecke eines Gefäßes, nicht nur an einer einfachen Teilung, sondern in einer mehrfachen Gabelung etabliert, oder daß er zwischen einem Komplex von Gefäßen an seinen Enden ausgespannt ist. Aber auch bei Berücksichtigung aller dieser Schwierigkeiten ließ sich eine Wandveränderung der Herdgefäße oft ausschließen, am leichtesten natürlich an den jungen und an den nicht kompakt gewordenen, bzw, an den atypischen Herden.

Zur Illustration dieses Verhaltens habe ich den bereits erwähnten kleinen Herd, der im übrigen dem typischen Bilde entspricht, hier wiedergegeben (Abb. 25). Es ist ein Herdchen, das sich nur über $30 \mu$ verfolgen läßt und das also eine bestimmte Herdform nur in den 2 Schnitten, die hier wiedergegeben sind, erkennen ließ. Hier ist das Herdgefäß klar und scharfrandig; bei Abblendung sieht man auch im Nisslpräparat die feine elatische Lamelle. Von einer Nekrose der Gefäßwand ist nichts zu sehen,. nicht einmal von einer auch nur leichten regressiven Umwandlung oder von einer progressiven Veränderung der Intimazellen.

Ebenso wichtig wie die besonders gut analysierbaren jungen oder auch manche weitentwickelten Herde sind natürlich die Bilder von den atypischen herdartigen Wucherungen. Es kann dagegen kein Einwand gemacht werden, diese den typischen Herden analog zu setzen. Die lokalisierten strauchartigen Gliawucherungen sehen ja besonders in der oberen Kleinhirnrinde durchaus den Bildern ähnlich, die wir an den Polen eines Herdes wahrnehmen können (vgl. Abb. 2 u. 3 bei $p h$ ).

Hier ist es nun recht leicht, die Gefäße durch das weit und locker angelegte plasmatische Maschenwerk der Glia zu verfolgen. Die beigegebenen Bilder zeigen das. Der Beweis ist hier also einfach zu hringen. 
daß das ,Gliastrauchwerk" nicht als Reaktion auf eine primäre Veränderung der Gefäßwand entsteht. Gerade deshalb auch erscheint mir der Befund reichlicher derartiger atypischer Herde zumal in dem einen Falle (Fall B.) von. Bedeutung, weil diese Bilder die Frage der Pathogenese der Herde gut klären helfen, und dann auch, weil sie - mehr als das sonst wohl geschehen wäre zu der Prüfung Anlaß geben, ob auch sonst solche unvollständigen bzw. atypischen Herde neben den kompakten vorkommen.

Diese Fráge ließ sich auch für die anderen Fälle bestätigen. Damit - und das ist das zweite, was mir für die Pathologie des Fleckfiebers von Wichtigkeit erscheint - ist also bewiesen, daß die Fleckfieberherde sich nicht nur in der vielgenannten Knötchenform präsentieren können. In allen Fällen und in einigen meiner Beobachtungen in besonders auffälligem Maße kommen derartige atypische Herdchen vor. Thre häufigste Form ist das Gliastrauchwerk, der Rosettenherd und der Gliastern. Diese Feststellung hat deshalb eine ganz besondere Bedeutung, weil es sich bei derartigen Herden nicht um Wucherungen handelt, welche lediglich für das Fleckfieber charakteristisch sind. Gliasterne, wie sie in der Brücke und im Rückenmark und hier und da auch in anderen Teilen des Zentralorgans von mir gefunden wurden, sind auch bei ganz andersartigen Krankheiten nicht selten. Bei verschiedenen schweren Allgemeinerkrankungen kommen solche um ein kleines Gefäßchen ringförmig gestellte Gliazellwucherungen vor; von solchen Gliaringen gehen dann oft nach der Peripherie die plasmatischen Gliazellfortsätzchen aus - Bilder, die von Nissl und seiner Schule als „Gliasterne" bezeichnet wurden. Stellen sich die Zellen um die Gefäßwand nicht einfach ringförmig, sondern verankern sie sich mit dem einen Fortsatz am Gefäß und streben sie mit dem anderen zentrifugal, sind sie also senkrecht zum Gefäßrohr als lang ausgezogene stäbchen- oder wurstförmige Zellen gestellt, so kommt ein Bild zustande, wie ich es hier als Rosettenherd an einer Serie demonstriert habe (Abb. 20).

Aber nicht nur für diese Gliasterne, sondern yor allen Dingen auch für das „Gliastrauchwerk" ist hervorzuheben, daß es nicht ausschließlich beim Fleckfieber vorkommt. Herr Geheimrat Nissl machte mich darauf aufmerksam, daß er einmal in einem Falle von Typhus abdominalis ${ }^{1}$ ) etwas Ähnliches gesehen hatte. Ich habe

1) Das uns zur Einsicht freundlichst überlassene Krankenblatt der Medizinischen Universitätsklinik in Heidelberg ergab für diesen Fall keine klinischen Besonderheiten. Der Kranke starb in dem Stadium der Erkrankung, wo sich die Schorfe von den Darmgeschwüren eben abzustoßen begannen. Er war in den beiden letzten Tagen vor dem Tode bewußtlos, delirant, später mehr kataleptisch. 
das mir gütigst überlassene Material verarbeiten können und fand in regionär außerordentlich verschiedenem Grade, aber immer nur vereinzelt eine fleckförmige, grobmaschige Wucherung der Gliazellverbände. Besonders ausgesprochen ist dies in dem Präparat, das hier in Abb. 24 wiedergegeben ist. Auch hier ist an den GefäBchen der Mole kularschicht des Kleinhirns nichts Pathologisches zu sehen. Die gewucherten Gliazellen stehen in weitmaschiger Verbindung miteinander. Die Ähnlichkeit bzw. morphologische Gleichartigkeit mit dem sogenannten gliösen Strauchwerk beim Fleckfieber ist unverkennbar.

Ob dieser Befund beim Typhus abdominalis regelmäßig oder doch häufiger vorkommt, vermag ich noch nicht zu entscheiden. Es ist aber sehr bemerkenswert, daß ein neuer (zweiter) Fall von Ty ph us, den ich daraufhin untersuchen konnte, neben schweren Veränderungen an bestimmten grauen Kernen, vor allem auch wieder - in ganz gleicher Weise fleckförmig - eine stra uchartige Gliawucherung in der Molekularschicht des Kleinhirns erkennen ließ, die durchaus der in dem erwähnten Fall gleicht, und damit also auch dem Gliastrauchwerk beim Fleckfieber. Die Untersuchungen über die fraglichen Veränderungen beim Typhus abdominalis sollen weiter fortgesetzt ${ }^{1}$ ) und es muß ermittelt werden, ob wir vielleicht bei anderen Infektionskrankheiten und bei schweren Allgemeinerkrankungen außer den Gliasternen eine herdförmige Wucherung der Gliazellen in jener eigentümlichen Stra u chbild ung sehen (s. S. 41). -

Die Ergebnisse dieser Untersuchungen betreffen drittens den Aufbau der Herde. Die beigegebenen Bilder der zentralen Herde geben eine Utbersicht über die Zellelemente, welche den Herd zusammensetzen, und sie zeigen, wie verschiedenartig im einzelnen Falle auch die gewöhnlichen Herde sein können und wie in manchen Fällen das eine oder andere Bild besonders häufig oder in besonders ausgeprägter Weise vorkommt. Alle Herde beim Fleckfieber haben gewiß eine außerordentlich große Familienähnlichkeit; aber sie unterscheiden sich doch bezüglich der Zusammensetzung nicht unwesentlich.

Im Zentralorgan sind sie meines Erachtens relativ leicht nach ihrer Zusammensetzung zu analysieren. Gewiß liegen die Dinge auch an den zentralen Herden immer noch überaus kompliziert. Wenn sie mir aber relativ einfacher erscheinen, so liegt das nicht allein daran, daß mir persönlich die Bauverhältnisse anderer Organe weniger bekannt sind, sondern vor allem an dem Umstande, daß im Zentralorgan eine reinliche Scheidung zwischen den mesenchymalen Be-

1) Anmerkung bei der Korrektur: Siehe den inzwischen erschienenen Aufsatz ,Eine Kleinhirnveränderung beim Typhus abdommalis“. Münch. med. Wochenschr. 1919, S. 313 . 
standteilen und dem ektodermalen Gewebe besteht. Die Gefäßwand ist von der ektodermalen Substanz durch die gliöse Grenzschicht getrennt. Und wenn es zu perivasculären Wucherungen im Zentralorgan kommt, ist es hier anders wie bei anderen Körperorganen, in welchen die Gefäße in dem Bindegewebsapparat des betreffenden Organes stecken und keine scharfe Grenze der mesenchymalen Bauelemente besteht. Die besondere, nicht mesenchymale "Stützsubstanz ${ }^{\text {c }}$ - der nicht nervöse ektodermale Apparat des zentralen Gewebes, die Glia - gestaltet die histopathologischen Bilder auch eigenartig.

Gerade mit Rücksicht auf die in der Literatur viel erörterten Bilder einer Wucherung von Gefäßwandelementen auf die circumscripte Wandnekrose habe ich nachdrücklichst zu betonen, daß ich davon im allgemeinen nichts sah; oder anders ausgedrückt, daß weder eine Nekrose noch eine reaktive Wucherung von Gefäßwandelementen das Wesentliche bei den Fleckfieberherden ist. Denn bei den meisten der gut entwickelten Herde ließ sich mit Sicherheit feststellen, daß lediglich die Wucherung der Gliazellen den Herd a usmacht. Das gilt, wie ja schon wiederholt dargelegt, für die strauchartigen Gliawucherungen, für die Rosetten und auch für typische kompakte Herde. Die Darstellung, die ich vorhin davon gegeben habe, und die beigegebenen Abbildungen dürften das beweisen. Sehr eindeutig sind besonders solche Bilder, wo das Herdgefäß wie in einem Muff von Gliazellen steckt, oder wo an einer breit aufgeschnittenen Teilungsstelle oder in einem Gefäßbogen die Gliawucherung sich den Adventitialelementen anlegt.

An der grundsätzlichen Bedeutung dieser Bilder für die Auffassung vom Wesen der Herde ändert es nichts, wenn wir hier und da an voll entwickelten Herden Intimazellen mit großen chromatinreichen Kernen und mit tiefer gefärbtem Plasma sehen. In einem meiner Fälle war ein solcher Befund zu erheben. Hier kam auch außerhalb von Herden eine einseitige und umschriebene Wucherung von Intimazellen zur Beobachtung, wie ich sie in Abb. 23 abgebildet habe. Aber ein solches Bild ist selten; progressive Umwandlung von Gefäß-, Intima- oder Adventitiazellen gehört jedenfalls nicht zu den charakteristischen Symptomen der Herde im Zentralorgan. Was diese zusammensetzt, ist in erster Linie die Neuroglia und in der Mehrzahl der Fälle ist es diese allein.

Fibroblastische Ele mente, wie wir sie doch bei einer Nekrose der Gefäßwand erwarten müßten, habe ich in den Hirnherden nie mals gesehen. Und so spricht auch gerade dieses Fehlen klar erkennbarer Fibroblasten nicht für eine ausgedehnte oder umschriebene wirkliche Gefäßwandnekrose. Was in den Herden zur Wucherung kom mt, sind Gliazellen; sie setzen den Herd zusammen und sie sind es vor 
allem auch, welche klar erkennbar im Frühstadium der Herde proliferieren. An den Herden anderer Organe ist es, wie angedeutet, natürlich sehr viel schwerer zu beurteilen, ob die mesenchymalen Elemente des Herdes der Gefäßwand entstammen oder dem perivasculären Bindegewebe. Am Zentralorgan ist die Entscheidung relativ einfach. Es sind keine Gefäßwandelemente, überhaupt keine mesenchymalen Zellen, sondern die um das Gefäß angeordneten Gliazellen, welche in Wucherung geraten.

Ausdrücklich sei hervorgehoben, daß für die sehr zahlreichen Zellen, die zumal in der Peripherie der Herde und in ihrer unmittelbaren Umgebung zu sehen sind, nämlich für die Stäbchenzellen, die gliöse Natur eindeutig bestimmt werden kann.

Wenn es in den beginnenden und auch in vielen gut entwickelten Herden, ebenso wie besonders bei den atypischen Wucherungen relativ leicht ist, den Gliacharakter der proliferierenden Zellen zu beweisen, so muß ich doch zugeben, daß für eine Reihe der kompakten Herde die Frage nicht absolut sicher beantwortet werden kann, ob nicht außer den Gliazellen auch mesenchymale Elemente mit dabei sind. Ich denke hier vor allem an jene Kerne, welche im Niss präparat ein nicht genau erkennbares Plasma um sich haben, und welche hakenförmig, wetzsteinartig oder merkwürdig rechteckig und abgeknickt erscheinen (s. S. 17). Wohin diese Elemente gehören, ist meines Erachtens nicht zu beantworten; sicher ist, daß sie nicht im entferntesten Fibroblasten ähneln. Aber auch von den gewöhnlichen progressiven Umwandlungsformen der Neuroglia weichen sie morphologisch ab. Es ist also nicht ausgeschlossen, daß sie vielleicht doch mesodermalen Ursprungs sind; aber ein Beweis läßt sich dafür meines Erachtens wiederum nicht bringen. Nur zwingen diese und einige andere nicht klar analysierbare Zellen zu der Erklärung, daß sich in manchen voll ausgebildeten und alten Herden das Vorkommen einzelner mesenchymaler Zellen nicht ausschließen läßt, wennschon es mir wiederum nicht möglich scheint, den sicheren Beweis für die mesenchymale Natur derselben zu erbringen. Oder anders ausgedrückt, wenn sich für die Elemente der meisten Herde und für die ganz überwiegende Mehrzahl der Zellen der anderen die Glianatur bestimmt behaupten läßt, so bleiben doch in manchen Herden einige Elemente übrig. deren gliöse Natur nicht behauptet und deren mesenchymale Herkunft möglich, wenn auch nicht sicher zu erweisen ist. (Bezüglich der weißen Blutzellen s. u.) -

Wenn also die Frage nach dem Anteil bindegewebiger Elemente am Aufbau der zentralen Herde dahin beantwortet werden kann, daß sie keine Rolle dabei spielen, so steht es mit den weißen Blut- 
elementen doch wesentlich anders. Gerade in deren Beimischung unterscheiden sich meines Erachtens die Gliaherdchen des Fleckfiebers recht voneinander: viele, und soviel ich sehe, die Mehrzahl (?) der Herde ist frei von leukocytären und lymphocytären Elementen. Aber in einer sehr großen Anzahl der Herde und in manchen Fällen besonders häufig und ausgesprochen finden sich weiße Blutzellen und ihre Fortentwicklungsformen.

Was zunächst die Leukocyten angeht, so ist mir aufgefallen, daß in einem meiner Fälle besonders zahlreiche Herde getroffen wurden, die sich zu einem großen Teile aus Leukocyten zusammensetzen. Sie liegen zwischen den gliösen Elementen. Und diese gliösen Elemente im Herde, ebenso wie die progressiv veränderten Formen der Glia der Umgebung zeigen, daß es sich hier ganz zweifellos um frische Herde handelt. Dafür spricht auch das Verhalten der Leukocyten selbst, die in den meisten solcher Herde keine Zerfallserscheinungen aufweisen. Das ganze Zellgefüge des Herdes ist noch locker. Nur selten zeigen die frischen Leukocytenherde am Herdgefäß, an dessen Wand und auch in seiner unmittelbaren Umgebung, Fibrinnetze. Man sieht solche Fibrinausscheidungen im Bereiche des Herdgefäßes mehr bei älteren Herden, dort, wo die Gefäßwand stärkere Schwellungen der Intimazellen und auch regressive Umwandlungen aufweist. Es ist diese Fibrinausschwitzung nur selten ein Zeichen der mit der Leukocytenauswanderung einhergehenden Exsudation von Blutflüssigkeit. Vor allem gibt es sehr viele Herde mit starker Leukocytenauswanderung ohne solche Fibrinausscheidung; in dem erwähnten Falle mit auffallend zahlreichen „Leukocytenherden" habe ich fast nie Fibrinausschwitzungen nachweisen können. Frische Herde mit mehr oder weniger reichlichen Leukocyten, die auch über den Herd hinaus im Gewebe verstreut erscheinen (Abb. 26), kommen auch in solchen Fällen vor, die im übrigen vorwiegend Herde älteren Datums ohne alle Leukocytenbeimischung zeigen.

Letzteres beweist, daß die Herde nicht etwa alle gleichen Datums sind. Ich kann mich daher der hier und da geäußerten Meinung, wonach die Aussaat der Herde über das Nervensystem gewissermaßen in einem Zuge stattfindet, nicht anschließen. Außer den frischen, viele Leukocyten enthaltenden lockeren Herden findet man neben alten kompakten oder schon regressiv veränderten, auch junge herdförmige reine Gliazellwucherungen, also ebenfalls beginnende Herdchen. In einem Falle war es bemerkenswerterweise so, daß sich in Herden der Großhirnrinde vielfach bereits Zerfallserscheinungen fanden, während im Hirnstamm frische oder doch voll entwickelte Herde lagen, die kein Zeichen der Rückbildung aufwiesen. So sind also gerade diese frischen Leukocytenherde ebenso wie die ausschließlich aus proliferierten jungen Gliazellen bestehenden Herdwucherungen auch 
deshalb von Wichtigkeit, weil sie uns lehren, daß der zur Herdbildung führende Prozeß längere Zeit wirksam ist.

Aber kehren wir wieder zu der Besprechung der Verschiedenheiten des zelligen Aufbaues der Herde zurück, so wirft sich von selbst die Frage auf, ob denn die Leukocytenherde immer frischen Datums sind. Es läßt sich leicht zeigen, daß es auch Herde gibt, die eine erhebliche Gliazellwucherung und bereits regressive Metamorphosen an den Gliaelementen aufweisen, und wo auch die Leukocyten vereinzelt Zerfallserscheinungen bieten. Die Leukocyten liegen hier mehr im Zentrum des Herdes. Solche alte, Leukocyten führende Herde gibt es auch in den Fällen, wo frische „Leukocytenherde" nicht oder nur selten gefunden werden. Oft sind die Leukocyten dann mit 1 y m phocytären Elementen vergesellschaftet, und noch häufiger trifft man in den voll a usgebildeten und alten Herden lediglich ly mphoc ytäre Elemente. Abb. 27 gibt ein Beispiel dafür. Hier sind die Leukocyten sehr spärlich, die lymphocytären Elemente reichlicher. Wie wir es beschrieben haben, kommen neben vereinzelten gewöhnlichen kleinen Lymphocyten auch große Mononucleäre und vor allem Vorstufen von Plasmazellen und voll entwickelte Plasmazellen vor. Vielfach haben diese die Neigung, sich rasch zurückzubilden. Die Kernmembran wird undeutlich, der Kern schrumpft etwas, und die der Kernwand anliegenden Chromatinbrocken buckeln gewissermaßen den Kern etwas vor. Die Kerne werden schließlich zu einem runzeligen oder höckerigen tief blauschwarz gefärbten Gebilde. Die Zellen werden kleiner und zerfallen, (Abb. 27).

In den frischen, zahlreiche Leukocyten führenden Herden habe ich lymphocytäre Elemente nicht oder nur vereinzelt gefunden. In den älteren Herden sind sie sehr häufig und verteilen sich, immer in Einzelexemplaren, über den Herd. Schätzungsweise findet man in einem Herd, wenn die lymphocytären Elemente zahlreich sind, acht bis zehn in einem Schnitt.

Sind nun diese Herde, welche mehr oder weniger zahlreiche Lymphocyten und ihre Fortentwicklungsformen enthalten, aus ursprünglichen Leukocytenherden entstanden? Das dürfte für einen Teil von ihnen zutreffen; aber gewiß nicht für die Mehrzahl der Herde. Denn ich habe in einigen Fällen, wo frische Leukocytenherde so gut wie nicht vorkommen und wo sich dennoch viele junge von Infiltratzellen freie Herde fanden, in einer sehr großen Reihe von älteren Herden lymphocytäre Elemente zwischen den Gliazellen verstreut gesehen. Dieser Befund spricht gegen die naheliegende Vermutung, daß nämlich wie sonst bei Entzündungen auch hier immer das Primäre die Leukocytenauswanderung sei, und daß dann die lymphocytäre Reaktion und die Proliferation komme. Daß der Gang des Prozesses, resp. die Herd- 
bildung immer oder überwiegend eine derartige ist, muß in Abrede gestellt werden, und damit kommen wir wieder zu dem Ausgangspunkt zurück, der uns in dem dritten Hauptteil dieser Ergebnisse beschäftigt, nämlich zu der Verschiedenheit in der Art und in dem Aufbau der Herde. Die Antwort darauf kann ich etwa dahin zusammenfassen: Es gibt junge Herde, in denen die Leukocyten sehr reichlich sind und an Zahl den gewucherten Neurogliazellen fast gleichkommen. In diesem und jenem Falle sind solche Herde besonders zahlreich. In der Mehrzahl der Fälle sind aber die Leukocyten führenden Herde wesentlich seltener als diejenigen, die lediglich aus dicht gewucherten Neurogliazellen aufgebaut sind. Vielfach bleibt auch bei der weiteren Ausbildung und bei der beginnenden Rückbildung der Herde ihre Zusammensetzung aus Gliazellen rein, und es fehlen Beimischungen weißer Blutzellen. Auf der Höhe der Entwicklung und noch häufiger bei regressiver Metamorphose der gewucherten gliösen Elemente können aber vereinzelte Leukocyten und vor allem lymphocytäre Elemente letztere auch gern allein - auftreten. Auch in Fällen, in denen man frische Leukocytenherde nicht oder ganz selten sieht, und in denen ausschließlich die Gliawucherung den beginnenden Herd kennzeichnet, sieht man oft in den Knötchen weiße Blutelemente in geringer Zahl über das Zentrum und die peripheren Zonen derselben verstreut. Daß endlich auch manche anfangs reichliche Leukocyten führenden Herde später lymphocytäre Elemente enthalten, ist nicht zu bezweifeln.

Am Herdgefäß (in dessen Verlaufe durch den Herd) oder an den Capillaren, die den Herd und seine periphere Zone durchlaufen, sieht man fast niemals lymphocytäre Elemente. Sie liegen vielmehr frei im Gewebe des Herdes. Andererseits findet sich ungemein häufig ein deutliches oder sogar starkes Plasmazellinfiltrat im Adventitialraum der in der Nähe des Herdes gelegenen Gefäße. Besonders oft ist es so, daß nur ein einzelnes, etwas größeres Gefäßchen diese starken Plasmazellinfiltrate beherbergt, während die anderen nur die geringe Einlagerung von Plasmazellen darbieten, wie sie in der Rinde durchschnittlich gefunden wird. Gerade jenes einzelne Gefäß mit dem starken Infiltrat hebt sich oft markant heraus, so wie das die Photogramme 6 und 12 wiedergeben. Vielfach konnte ich feststellen, da $\beta$ jenes hauptsächlich infiltrierte Gefäß der etwas größere Stamm ist, welcher als Ast das Herdgefäßchen abgibt. Was das zu bedeuten hat, vermag ich nicht zu sagen. Es verlangt aber dieser so auffällige Befund des Fehlens von Infiltraten im Herdgefäß bei Anwesenheit lymphocytärer Elemente im Herd und das starke Infiltrat an einem zum Herde in (indirekter) Verbindung stehenden Gefäß (Ursprungstamm des Herdgefäßes) besonders hervorgehoben zu werden. Dabei sieht man übrigens ein reines Plasmazellinfiltrat wohl ebenso häufig, wo die Leukocytenherde 
besonders zahlreich sind, wie dort, wo es mehr reine Neurogliazellherde oder ältere mit vereinzelten lymphocytären Elementen gibt.

Was a us dem Herd wird, vermag ich nicht zu sagen; man wird - wie Fränkel es verlangt -- nach der Untersuchung solcher Fälle trachten müssen, die nach Ablauf der Krankheit gestorben sind. Es wäre natürlich von allergrößtem Interesse zu sehen, was die herdförmigen und die anderen Veränderungen schließlich als Endzustand hinterlassen. Ich habe die Herdchen nur bis zu dem Punkte verfolgen können, von dem hier die Rede war, nämlich bis dahin, wo sich regressive Umwandlungen an den Bauelementen der Herde vollziehen, und wo der Herd im Zentrum lichter wird, vornebmlich durch Zerfall der gliösen Elemente, während die Peripherie noch zellreich ist. Diese zentrale Lichtung des Herdes kommt wohl auch dadurch zustande, daß die dort ansässigen Teile des spezifisch nervösen Parenchyms mit zugrunde gehen. Die Ganglienzellen, die auffallend lange im Herde eine leidliche normale Struktur bewahren können, zerfallen. Man sieht nicht selten einen zerstörten Kern zu feinem Chromatinstaub zerstreut. Auch von den nervösen Fasern kann man sich etwa am Markscheiden- und besonders an dem Alzheimerschen Mallorypräparat überzeugen, daß sie längere Zeit in dem Herd persistieren können; sie sind in dem derben, wie gequollen und bröckelig erscheinenden Gliaprotoplasma eingebettet und gehen auch erst verhältnismäßig spät zugrunde. Wie sich dann aber der eigentliche Herd umwandelt, weiß ich nicht zu sagen. Auffallend ist nur, daß wir niemals einen Ansatz von Gliafaserbildung an den Gliazellen des Herdes und auch nicht an denen der Umgebung wahrgenommen haben. Ebensowenig aber ließ sich eine Entwicklung von Bindegewebsfibrillen feststellen. Es wurde danach mit der Tanninsilbermethode gefahndet; niemals hat sich irgendwo eine Neubildung von Fibrillen gezeigt. Allermeist war, wie schon erwähnt, der Befund am Gefäßbindegewebe, auch des Herdgefäßes normal. Und wo er es nicht war, zeigten sich lediglich regressive Umwandlungen, die sich bei dieser Methode vor allem in Aufhebung der Färbbarkeit jener Fibrillen bemerkbar machte ein Befund, der zusammen mit den früher erwähnten darauf hinwies, daß ja an der Gefäßwand auch des Zentralnervensystems Schädigungen der Gefäßwand vorkommen. Käme aber eine wirkliche Nekrose der Gefäßwand zustande, zumal wenn sie nur in circums ripter Weise das Rohr beträfe, so würde man doch gewiß fibroblastische Elemente mit Differenzierung von Fibrillen erwarten dürfen.

Es hat keinen Zweck zu prophezeien, was mit den Herdchen im Zentralorgan wird. Es ist das auch gerade bei Gliawucherungen eine zum mindesten mißliche Sache; wir erleben hier immer Überraschungen. Es könnte ja sein, daß in den gliafaserreichen Gebieten, wie in der obersten 
Groß- und Kleinhirnzone und im Hirnstamm und Rückenmark eine Wucherung der Gliafasern einsetzt und an die Stelle des Zellherdes tritt. An den Herden der Haut hat Eugen Fränkel mit dem Kernarmwerden des Zentrums der Roseolenplaque eine wohl bindegewebige Umwandlung gesehen; während die Peripherie des Knötchens noch kernreich (8. Krankheitswoche!) war, schien sich im Zentrum eine bindegewebige Metamorphose $\mathrm{zu}$ vollziehen. Es wäre danach und nach den Erfahrungen allgemein neurohistologischer Art möglich, da $\beta$ in den erwähnten Gebieten des Zentralnervensystems in späteren Phasen der Umbildung der Herde die faserige Neuroglia an die Stelle tritt. Daß Bindegewebe hier die Organisation der Knötchen übernimmt, ist nach der Zusammensetzung der Herde und der Wahrung der gliösen Grenzschichten beim Fleckfieber auszuschließen; nur in den selteneren Herden mit gröberen Gefäßwanddestruktionen könnte sich das mesenchymale Gewebe an der endlichen Organisation beteiligen. Für die Rinde werden wir eine Gliafasersubstituierung der Knötchen - bei der normalen Anlage der fasrigen Glia und bei der Reaktionsweise der corticalen Gliazellen -- schwerlich erwarten. Aber wir dürfen uns auch nicht wundern, wenn etwa für das gliöse Strauchwerk in der Molekularzone oder für die Herde in dem Hirnstammgebiet ebenfalls die Faserproliferation ausbleibt. Es bleibt also die Notwendigkeit, abgelaufene, alte Fälle in dieser Richtung zu durchforschen.

Mit den Herden, ihrer Eigenart, den Verschiedenheiten ihrer Form und ihrer zelligen Zusammensetzung ist das histologische Bild beim Fleckfieber nicht erschöpft. Wir kommen in der Fleckfieberpathologie schließlich zu den diffusen Veränderungen am Nervensystem, den Infiltrationen an den zentralen Gefäßen, den Zelleinlagerungen in die weichen Häute und den Zerfallserscheinungen des nervösen Parenchyms.

Nach dem, was wir sahen, ist es gewiß berechtigt, die ly mphocytären Infiltrationen an den zentralen Gefäßen zu den diffusen Veränderungen zu rechnen. Gewiß stehen manche der Infiltrate in engsten Beziehungen zu den Herden; ich erinnere daran, daß dort, wo viele Herde sind, auch die Gefäße regelmäßig durch gröbere Plasmazellinfiltrate schon im Ubersichtsbild herausgehoben sind, und ich weise nochmals auf den sehr in die Augen springenden Befund hin, daß oft gerade ein einzelnes Gefäß - meist das Stammgefäß, welches das "Herdgefäßchen" abgibt - ein auffallend intensives Infiltrat zeigt. Gerade für diesen Befund wurde ja hervorgehoben, daß die Infiltration offenbar ,irgend etwas mit dem Herd zu tun hat", zumal die mehr isolierte Infiltration eines Gefäßes dort, wo wenig Herde und wenig Infiltrate sind, in der unmittelbaren Nähe des 
Herdes mit aufdringlicher Deutlichkeit aufzutreten pflegt. Muß man also für solche Gefäßinfiltrate den Zusammenhang mit der Herdbildung notwendig annehmen, so doch keineswegs für jene Infiltrationen, die vielmehr als diffuse Veränderungen einen wichtigen Faktor im histologischen Prozeß bilden. So bestehen in dem Schnitte, Abb. 7, sehr ausgebreitete Gefäßinfiltrationen, besonders auch der kleineren Rindengefäße, und Herde fehlen fast ganz. Zwei meiner Fälle zeigten dieses Verhalten recht häufig; bei ihnen fanden sich ausgebreitete und diffuse Plasmazelleinlagerungen in die adventitiellen Scheiden, - ,,diffus" wenigstens in einzelnen Mantelteilen oder anderen zentralen Gebieten. Soviel ich sehe, finden sich solche Infiltrationen auch in anderen Körperorganen ebenfalls ohne unmittelbare und lokale Beziehungen zu den Herden; ausgebreitete leukocytäre Infiltrationen, wie ich sie vielfach in der Haut traf, habe ich in der Hirnrinde und überhaupt im Zentralorgan nie gesehen. Das Gefäßinfiltrat ist hier fast lediglich lymphocytär. Es enthält eben Lymphocyten und vor allem Plasmazellen; wie wir das zu sehen gewöhnt sind, werden die Lymphocyten reichlicher, wo - ausnahmsweise - das Infiltrat intensiver ist. Selten mischt sich hier und da ein Leukocyt unter, ähnlich wie - etwas häufiger — in den Meningen. Die Intensität und die Ausbreitung der adventitiellen Infiltrate steht in keinerlei Beziehungen zur zelligen Zuisammensetzung der Herde. Man könnte vielleicht vermuten, daß sie sich besonders dort finden, wo sich viele weiße Blutzellen an der Zusammensetzung der Herde beteiligen. Ich sah im Gegenteil in dem mehrfach erwähnten Falle mit reichlichen leukocytenhaltigen Herden nur ein relativ spärliches Infiltrat der Gefäße; ebenso war die Infiltration dort keineswegs intensiver, wo sich älteren Herden mehr lymphocytäre Elemente beimischten. Auch insofern wird also dieses diffuse Infiltrat der Gefäße nicht durch die Herde bestimmt.

Alles in allem können wir demnach sagen, daß sich beim Fleckfieber mit Regelmäßigkeit, aber mit erheblichen Schwankungen in der Intensität ein mehr oder weniger diffuses, bzw. an bestimmten zentralen Gebieten akzentuiertes Plas mazellinfiltrat der zentralen Gefä Be findet - außer der Infiltration, die häufig das, bzw. die in unmittelbarer Nähe eines Herdes gelegenen Gefäße betrifft.

Von den zelligen Einlagerungen in die Meningen wurde ebenfalls schon hervorgehoben, daB lokale Beziehungen zu ihrer Art und Reichhaltigkeit einerseits und den Herden im nervösen Gewebe andererseits nicht bestehen. Wenn wir in der Regel in den Fällen, wo reichliche Herde vorkommen, auch besonders dichte Zellenmassen in der Pia sehen, so drückt sich darin wohl nur die Intensität des Prozesses aus, bzw, der Grad, in welchem eben das zentrale 
Nervensystem von dem Prozesse befallen ist. Aber lokale Beziehungen zwischen meningealem ,Infiltrat" und Herden bestehen nicht. Dafür sprechen ja unter anderem die Bilder von den Hinterhauptslappen, wo die Zelleinlagerung in die Meningen sehr reichlich und die Herde doch überaus spärlich sind, und noch mehr die Bilder von der Brücke, die ja ganz besonders große Mengen von Herden enthält und an der doch die Pia ähnlich wie im Rückenmark nur ein geringfügiges Infiltrat beherbergt.

Während wir bei der Schlafkrankheit und der Paralyse von einer Infiltration sowohl der Meningen wie der zentralen Gefäße sprechen, erscheint das aus den schon angegebenen Gründen beim Fleckfieber nicht wohl angängig. Es bestehen hier erhebliche Unterschiede der zelligen Einlagerungen in die adventitiellen Lymphräume der zentralen Gefäße einerseits und der Meningen andererseits, und man kann diese sehr verschiedenartigen pathologischen Zelleinlagerungen einander nicht gleichsetzen. Die Meningen beherbergen vor allem Makrophagen, d. h. Elemente, die nichts mit weißen Blutzellen zu tun haben und die in überwiegender Anzahl Zeichen ihrer Freßtätigkeit aufweisen; an den zentralen Gefäßen dagegen haben wir es im allgemeinen mit dem gewöhnlichen lymphocytären resp. plasmacytären Infiltrat zu tun. Man kann also hier nicht schlechthin von einer ,chronischen Meningitis" sprechen, wie etwa bei der Paralyse oder der Schlafkrankheit, und kann die Zelleinlagerung der Meningen nicht der an den zentralen Gefäßen analog setzen. Immerhin wird die Differenz zwischen Meningeal- und Adventitialinfiltrat stellenweise überbrückt und sogar ausgeglichen, einmal indem auch in den Meningen ein lymphocytäres Infiltrat mit besteht, welches histologisch ähnlich bewertet werden darf, wie das an den zentralen Gefäßen. Dann aber auch dadurch, daß - relativ selten freilich, z. B. an einigen langen Markgefäßen und an Gefäßen der basalen Ganglien (s. S. 21) - die Zelleinlagerung, insbesondere die Mischung von Makrophagen mit lymphocytären Elementen ganz der in den Meningen entspricht. Davon wird nachher noch die Rede sein. (s. S. 38).

Da diese ausgebreitete Durchsetzung der Meningen mit Makrophagen. (d. h. mit großen, blasenförmigen Zellen, die einen relativ kleinen, in der Peripherie gelegenen, wechselnd gestalteten Kern, ein intensiv gefärbtes, feinwabiges Ektoplasma und Zelleinschlüsse haben) regelmäßig beim Fleckfieber vorkommt, so muß diese besondere Form der meningealen Zelleinlagerung als ein wichtiges Sondersymptom im histologischen Gesamtbild dieses Prozesses herausgehoben werden.

Diffus sind endlich die in allen meinen Fällen vorhandenen, leichten degenerativen Veränderungen am funktiontragenden nervösen Parenchym. Diese sind freilich im allgemeinen nicht unmittelbar an den spezifisch nervösen Gewebsbestandteilen zu erkennen. Es sind sogat 
die Veränderungen an den relativ leicht analysierbaren Ganglienzellen nur gering; ich möchte sagen, sie sind hier keineswegs stärker und ausgebreiteter, als man bei der Schwere der Gesamterkrankung erwarten muß. Das Zellbild entspricht im großen und ganzen dem, wie wir es bei vielen schweren infektiösen und toxischen Allgemeinerkrankungen sahen. Darüber hinaus aber fällt doch (in der Hirnrinde und auch in anderen Teilen des Zentralnervensystems) eine erhebliche Zunahme des gliösen Protoplasmas, progressive Umwandlungen der Gliazellkerne, intensivere Färbung der Gliastippchen auf. A möboide Gliazellen habe ich bemerkenswerterweise in keinem meiner Fälle gefunden; Stäbchenzellen sind in der Groß- und Kleinhirnrinde häufig. Die ausgebreiteten progressiven Umwandlungen der zelligen Glia geben einen Index dafür, daß hier auch feinere diffuse Zerfallsvorgänge sich abspielen. Das wird noch weiter bewiesen durch Abbaustoffe. Während wir an den Markscheiden- und Fibrillenpräparaten der Rinde und des Markes keine deutlichen Lichtungen nachweisen können, zeigt die Ansammlung von mit Fett beladenen gliösen Transportelementen in unmittelbarster Umgebung der Gefäße und auch in ihrem Adventitialraum, daß hier nervöses Gewebe zerfällt (Abb. 36). Wenn auch diese Zerfallserscheinungen keinen größeren Umfang haben, so habe ich sie doch mit ziemlicher Regelmäßigkeit gerade im Markradius gesehen.

Wie ich sagte, haben die Befunde beim Fleckfieber über die spezielle Anatomie dieses Prozesses hinaus ihre Bedeutung für die allge meine Pathologie des Zentralnervensystems, insbesondere für die Rindenanatomie. Und das ist der eigentliche Anlaß, weshalb ich hier die pathologische Anatomie des Fleckfiebers ausführlicher besprochen und mit Abbildungen belegt habe; den Rindenpathologen geht das Fleckfieber nur deshalb so viel an, weil daran wichtige, allgemein histopathologische Symptome in prägnanter Weise hervortreten.

Es ist zunächst die Frage der Herkunft der Plasmazellen, Makrophagen und Stäbchenzellen, welche die Bilder beim Fleckfieber der Beantwortung näher bringen.

Was die Entstehung der Plasmazellen anbelangt, so meine ich allerdings nicht, daß das Fleckfieber unsere Kenntnis über die letzte Herkunft lymphocytärer Elemente wesentlich förderte. Nachdem vor allem Marchand die Frage der Herkunft der Lymphocyten bei den chronischen Entzündungen auf das ausführlichste und in einer nach dem Stand unserer Kenntnis zunächst abschließenden Weise beantwortet hat, entfällt jeder Grund, hier auf diese Dinge wieder einzugehen. Und das um so mohr, als sich unter den verschiedenen Körper- 
organen und Geweben das Zentralnervensystem wohl am wenigsten für die Entscheidung des Problems eignet, woher denn die Massen von lymphocytären Elementen bei chronischen Entzündungsprozessen kommen. Die Bilder vom Fleckfieber geben jedoch Auskunft über die Frage der Entwicklung der Plasmazellen aus Lymphocyten und ihre genetischen Beziehungen zu diesen. Die meisten Autoren stehen ja heute, gerade wie die Diskussion zu dem Marchandschen Referat gezeigt hatte, auf dem Standpunkt, daß die Plasmazellen sich aus den Lymphocyten als deren Fortentwicklungsformen bilden. Man kann das wohl kaum so sinnfällig beweisen wie hier an den meningealen Infiltraten beim Fleckfieber (vgl. Abb. 32 u. 33). Neben ihrer Vermehrung durch Mitose geht ihre Neubildung aus Lymphocyten. Wir sehen die Zunahme des Plasmas um den Lymphocytenkern, die stärkere Metachromasie des Plasmaleibes, die Ausbildung des hellen Hofes und das allmähliche Hervortreten eines mehr schwammigen Baues des Außenbezirkes des Zelleibes. Die Entstehung des hellen Hofes ist an vielen solchen Vorstufen von Plasmazellen gut zu erkennen; das Auftreten feinlöcheriger Hohlräume, die keineswegs immer in der Umgebung des Kernes, sondern oft mehr peripher entstehen und die dann mit dem Wachsen des Zelleibes mehr zentral rücken; die Zunahme und Vergrößerung dieser Hohlräume zu einem einheitlichen hellen Bezirk in der Zelle. Interessant ist auch gerade die Anpassung dieser jungen Plasmazellen an den ihnen zur Verfügung stehenden Raum. Vielfach sind in den Gefäßen der Rinde kleine Plasmazellen zu sehen, die einen nur wenig ausgebildeten Hof haben, recht intensiv gefärbtes chromophiles Plasma und einen typischen Kern zeigen und die hier im engen Adventitialraum sich in der üblichen Weise aneinander abplatten. Während hier schon diese jungen Plasmazellen durch die epitheloide Lagerung ihre kantige Form bekommen, behalten sie in den viel weiteren Räumen, die ihnen in den Meningen zur Verfügung stehen, lange Zeit eine kugelige oder ovale Gestalt und werden polyedrisch erst dort, wo sie durch das Engerwerden des Bezirkes, in welchem sie liegen, dazu gezwungen werden. Wie man all diese Dinge beim Fleckfieber leicht an einem engumgrenzten Bezirk verfolgen kann, lehrt Abb. 33.

Auch bei den Makrophagen läßt sich deutlich ihre Herkunft erweisen. Allerdings sind die verschiedenen Fälle und Hirngegenden nicht gleich günstig für eine solche histologische Analyse; denn vielfach erscheinen die Meningen mit Makrophagen dicht ausgefüllt und häufig fehlen sichere Zeichen fortdauernder Neubildung solcher Elemente. Aber an anderen Stellen wieder - und besonders klar in einem meiner Fälle, in welchem die Zelleinlagerung in die Meningen relativ geringfügig ist, - läßt sich die Entwicklung der Makrophagen aus den Deckzellen der meningealen Lymphräume bżw. aus Meningealzellen 
überhaupt gut erweisen. Die mesenchymalen Zellen werden plasmareicher; ihr Zelleib färbt sich stäiker; die langgestreckte Form wird allmählich in eine mehr plumpe Spindel umgewandelt. Mit der weiteren Zunahme des Protoplasmas und seiner Verbreiterung erscheinen die Zellen oval und runden sich allmählich mehr ab. Schon als plumpe Spindeln lösen sie sich offenbar vielfach aus dem ursprünglichen Verbande. Die ovalen Elemente können bereits als Cytophagen Zellreste in ihrem Innern führen. Mit der allmählichen Umgestaltung der ovalen in die Bläschenform wird das Protoplasma noch stärker färbbar, und es scheidet sich allmählich eine intensiv und leicht metachromatisch gefärbte feinwabige Außenschicht als Ektoplasma von dem übrigen Zellteile. Es kann also keinem Zweifel unterliegen, daß diese Makrophagen wie bei der Tuberkulose der Meningen und bei luetischen Prozessen Histiocyten (im Sinne Aschoffs) sind.

Die Makrophagen haben beim Fleckfieber auch insofern eine besondere Bedeutung, als sie wenigstens in einzelnen Fällen an den zentralen Gefäßen beobachtet werden konnten. Das erscheint gerade im Vergleich mit den tuberkulösen und luetischen Prozessen überaus u ngewöhnlich. Dort sind sie, abgesehen von den Stellen der Granulombildung, doch nur in den Meningen ausgebreitet, während die zentralen Gefäße davon frei sind, und zwar auch da, wo die darüber gelegene Pia damit vollgepfropft ist. Auch beim Fleckfieber ist es ja, wie wir mehrfach betonten, durchschnittlich ebenso, daß nämlich die Durchsetzung mit Makrophagen auf die Pia beschränkt ist und daß die Rinden- und Markgefäße durchschnittlich nur ein lymphocytäres Infiltrat führen. Aber das ist eben das Bemerkenswerte (besonders an zweien meiner Fälle), daß beim Fleckfieber auch lange Markgefäße und größere Arterien und Venen im Gebiete der basalen Ganglien eine recht erhebliche Menge solcher Makrophagen in ihren Adventitialscheiden führen können. Es handelt sich dabei nicht um eine Einschwemmung der Elemente aus den Meningealräumen; denn wir sehen, daß gerade die Gefäße der Rinde auch in den eben erwähnten beiden Fällen so gut wie ganz frei sind von Makrophagen und diese erst in den inneren Abschnitten des Hemisphärenhirnes und im Hirnstamm auftreten können. Ein solches Vorkommen von Makrophagen in zentralen Gefäßen erscheint — wie gesagt — nach den Befunden bei anderen Prozessen sehr ungewöhnlich.

Für die in den Adventitialräumen vorhandenen Makrophagen läßt sich ihre Genese ebenfalls aus seßhaften mesenchymalen Elementen erweisen. An einem Gefäß, wie es in $A b b .18$ wiedergegeben ist, ist das natürlich nicht möglich; denn hier liegen die Makrophagen dicht aneinander gedrängt und haben sich gegenseitig $\mathrm{zu}$ epithelartigen Gebilden abgeplattet. Aber an dem Schnitte, Abb. 17, ist das leichter 
möglich, und ganz besonders in jenem Falle, wo größere Gefäße der basalen Ganglien mit ihren weiten Adventitialräumen derartige Zellen beherbergen. Da ist es genau wie in den Meningen, daß sich die Eigenzellen der Adventitia allmählich zu plumpen, plasmareichen spindeligen und ovalen Gebilden umwandeln und schließlich Bläschengestalt annehmen. Wo der Raum sie dazu zwingt, lagern sich diese Makrophagen dicht aneinander und erscheinen polyedrisch - ebenso wie wir das an den Plasmazellen beobachten.

Sehen wir nun hier wesentliche Unterschiede bezüglich der Herkunft der Makrophagen einerseits, der Plasmazellen andererseits und zeigen diese beiden Zelltypen in der Mehrzahl ihre charakteristischen Merkmale und ihre morphologischen Unterschiede voneinander auf das klarste, so muß doch auf das nachdrücklichste hervorgehoben werden, $\mathrm{da} \beta$ es bei einer nicht unerheblichen Reihe von Zellen gar nicht möglich ist zu entscheiden: Haben wir es mit einer nicht typischen und vielleicht regressiv umgewandelten Plasmazelle zu tun oder mit einem, ebenfalls nicht scharf gekennzeichneten Makrophagen? Es scheint mir auffallend, wie hier die Makrophagen vielfach eine besonders starke Tingierung. und eine lebhafte Metachromasie ihres Ektoplasmas zeigen, und zwar auch an den sonst typischen Formen, d.h. die ausgesprochen blasenförmig sind, die einen relativ kleinen, peripher gestellten Kern haben, ein feinmaschiges Ektoplasma besitzen und Zellreste und andere Dinge in sich eingeschlossen halten. In anderen Elementen fehlen die Einschlüsse, der Kern ist relativ klein, besitzt aber nicht die Eigentümlichkeiten des Plasmazellkernes in der Anordnung des Chromatins, und die Zelle hat keinen hellen Hof; daneben sind andere Elemente, in denen der Kern groß ist, wiederum kein Kernwandehromatin zeigt und wo das Plasma im Innern vakuolär erscheint, so daß man nicht weiß: Handelt es sich um den hellen Hof einer Plasmazelle oder um eine von den häufigen vakuolären Bildungen eines Makrophagen? Es ließen sich recht viele solcher fraglichen Gebilde beschreiben, in denen man meines Erachtens ebensoviel Grund für wie gegen die Plasmazelloder die Makrophagennatur geltend machen kann. Man darf diesen Befund wohl in dem Sinne deuten, daß hier wie ja auch sonst Zellen ganz verschiedener Herkunft unter den gleichen Bedingungen morphologisch einander ähnlich werden. Derselbe Reiz, der auf sie einwirkt, oder dieselbe Funktion, die sie zu erfüllen haben, bedingen offen̈bar das ähnliche Aussehen histogenetisch verschiedenartiger Elemente. Wir kennen das ja auch von anderen Zellgebilden her; ich erinnere nur an die Körnchenzellen mesodermaler und gliogener Art.

Wahrscheinlich steht es ähnlich auch mit der Morphologie und der Histogenese der Stäbchenzellen. Aus den Paralysearbeiten Nissls und Alzheimers sind die Gründe bekannt, die sich für die 
mesodermale Natur der Stäbchenzellen geltend machen ließen. Alzheimer hat im Jahre 1912 noch einmal zu dieser Frage auf Grund neuerer Untersuchungen Stellung genommen und sich dahin geäußert, daß jedenfalls viele Stäbchenzellen auch bei der Paralyse gliogener Herkunft sind. Das kann ja nach den Untersuchungen Sträusslers, der gelegentlich eine Gliafaserbildung an solchen Zellen nachweisen konnte, und besonders nach den Mitteilungen Ach úcarros über die Stäbchenzellen bei der Tollwut keinem Zweifel unterliegen. Ebenso aber erscheint es nach vielem sicher, da $B$ es auch mesodermale Stäbchenzellen gibt. Dafür sprechen, wie auch Alzheimer hervorhebt, die Bilder, die man mit der Achúcarroschen Tanninsilbermethode erheben kann, wo Stäbchenzellkerne in den ins ektodermale Gewebe vordringenden Bindegewebszügen gelegen sind.

Beim Fleckfieber kann man, so deutlich wie bei keinem anderen Prozeß die Glianatur der Stäbchenzellen erweisen. Mit der besseren Kenntnis von der außerordentlichen Polymorphie der Gliazelle erschien es allmählich verständlicher, daß die wuchernden Gliazellen auch einmal diese Gestalt langer stäbchenförmiger Kerne mit weitausgezogenem polständigem Plasma annehmen können. Ułbergangsformen lassen sich fast immer leicht konstruieren. Man sieht bei der Paralyse wie bei der multiplen Sklerose (A. Westphal), bei der endarteriitischen Lues, wie auch unter tuberkulösen Granulomen stäbchen- und wurstförmige Elemente, die gliogener Herkunft scheinen. Beim Fleckfieber ist, wie gesagt, der sichere Beweis zu erbringen, daß sie sich hier von der Glia herschreiben. Beweiskräftig ist dafür nicht sowohl der Kern (der keine ganz sicheren Anhaltspunkte gibt), als vielmehr das Plasma. Die Stäbchenzellen führen in ihrem Protoplasma ungewöhnlich scharf gefärbte Nisslsche Stippchen; sie sind daran weithin kenntlich und gut verfolgbar. Sie überraschen fast noch mehr als bei der Paralyse durch den oft enorm in die Länge gezogenen Leib. Nicht immer ist ihr Zelleib ganz schlank, und vor allem ist er nicht scharfrandig. Gerade das aber ist das zweite Moment, das neben den Gliastippchen für die gliogene Natur der Stäbchenzellen im Rindenbilde des Fleckfiebers spricht: nämlich der feine Uberzug und Spitzenbesatz, den der Zelleib und vor allem auch jeder Fortsatz der stäbchen- und wurstförmigen Zellen zeigt. Ich verweise auf die Abb. $31^{1}$ ). Gewiß sieht man Stäbchenzellen, bei denen die Stippchen der Fortsätze und der Spitzenüberzug nicht entfernt so deutlich oder überhaupt nicht nachweisbar sind. Aber für die Mehrzahl der Zellen ist gerade auffallend die sehr feine Verzweigung des Plasmas mit eingestreuten chromophilen Stippchen und die unscharfe Abgrenzung des eigent-

i) Anmerkung bei der Korrektur: Vgl. dazu die Anmerkung aut S. 49. 
lichen Plasmaleibes wie seiner Fortsätze, die sich in die Umgebung verlieren.

So läßt sich also hier der Beweis erbringen, daß die Stäbchenzellen von Gliaelementen stammen. Damit ist aber nicht gesagt, daß sie bei allen möglichen Prozessen gliogen seien. Wennschon ich für die Paralyse und die multiple Sklerose annehme, daß sie auch hier vorwiegend gliogen sind, so kann es doch meines Erachtens keinem Zweifel unterliegen, daß a uch mesodermale Stäbchenzellen vorkommen. Für die Ausgestaltung dieser eigenartigen Elemente aus verschiedenen Zellarten sind wohl die gleichen Ursachen bzw. die gleichen Bedingungen wirksam. Beim Fleckfieber dürften es lediglich Gliaelemente sein, welche die Gestalt der Stäbchenzellen annehmen.

Für die Histopathologie der Hirnrinde sind weiter die am Kleinhirn beschriebenen fleckförmigen Gliazellwucherungen in der Molekularschicht von Bedeutung. Wir kennen ja fleckförmige Gliafaserwucherungen der obersten Kleinhirnschicht bei den syphilogenen zentralen Erkrankungen, vor allem bei der Paralyse und der Tabes. Ich brauche hier nur auf die oft erwähnten und jedem bekannten Feststellungen Weigerts hinzuweisen, die Alzheimer in seinen Paralysearbeiten eingehend erörtert hat. Beim akuten Prozeß des Fleckfiebers sehen wir an dem gliösen Strauchwerk im Kleinhirn keinerlei Andeutungen von Faserbildung; und auch beim Typhus abdominalis ist in den entsprechenden Herden davon nichts wahrzunehmen. Es fragt sich nun, wie bei der Paralyse und bei der Tabes a nfänglich die fleckförmigen Gliawucherungen aussehen, $d$. h. wie sich die circumseripte Wucherung der Bergmannschen Gliafasern einleitet und entwickelt. Das ist aus plausiblen Gründen bei diesen chronischen Prozessen nicht leicht zu entscheiden und das Nisslsche Zellpräparat, das wir hier - an Stelle des Weigertschen Gliafaserpräparates, welches uns ja nur den Endzustand zeigt - zu Rate ziehen müssen, gibt meist keine Antwort auf diese Frage. Denn eben auch im Nissl präparat finden wir oft nur fleckförmig eine Vermehrung der Zellkerne, die meist sehr starke regressive Umwandlungen erfahren haben, und von dem gliösen Protoplasma sehen wir nur dürftige Streifehen. Erschwert. wird die Prüfung der Kleinhirnbilder bei der Paralyse noch besonders durch die außerordentliche Vielgestaltigkeit, in der dieser Hirnteil an dem paralytischen Prozeß teilnehmen kann. Etwa vorhandene fleckförmige Wucherungen werden ja. vielfach durch diff use Ausfälle und Destruktionen der Kleinhirnrinde überlagert. Sehen wir aber von allen solchen Fällen ab, so findet man doch auch bei der Paralyse mitunter das, wonach wir suchen, 
nämlich frischere, plasmareiche circumscripte Gliazellwucherungen in der Molekularzone des Kleinhirns ohne gleichzeitige andere Veränderungen am gleichen Orte. Zwei solche Fälle habe ich bei einer Durchsicht von 10 paralytischen Kleinhirnen gesehen. Auch hier findet man breite plasmatische Verbände der gewucherten Gliazellen; in einem dieser beiden Fälle fehlte auch jedes Infiltrat an den Gefäßen der Kleinhirnrinde. Die Gliaplasmazüge ordnen sich in durchaus ähnlicher Form wie beim Fleckfieber und beim Typhusabdominalis zu einem mehr oder weniger umschriebenen Strauchwerk oder sie sind strichförmig gestellt. Man kann bei der Betrachtung solcher Bilder nicht entscheiden, ob sie diesen Prozessen oder eben der Paralyse angehören: in ihrer Gestalt und Anordnung lassen sich diese Veränderungen bei Paralyse nicht sicher von den hier geschilderten unterscheiden.

Wir sahen, daß das gliöse Strauchwerk in seiner charakteristischen Form nur in der obersten Schicht des Kleinhirns und in geringerem Maße und seltener in der obersten Großhirnrindenzone vorkommt. Sonst fanden wir es nicht. Das ist natürlich kein Zufall, ebensowenig wie das an die gleichen Gegenden gebundene Auftreten der Rosettenherde. Auch diese sahen wir ausschließlich in der ersten Schicht der Großhirnrinde und in geringerer Häufigkeit in der Molekularschicht des Cerebellums. Wenn nun auch in den eben genannten Gegenden typische Knötchen von den gleichen Baueigentümlichkeiten beobachtet werden, wie in allen anderen Teilen des Zentralnervensystems, so sind doch die Strauchbildung und das Auftreten der Rosettenherde - beide mit ihren eigenartigen Gliazellverbänden - an die obersten Zonen der Groß- und Kleinhirnrinde gebunden und kommen nicht wie die üblichen Knötchenherde allenthalben vor.

In diesen beiden Herdarten - dem Strauchwerk und der Rosettenbildung - zeigen nun die Gliazellen Besonderheiten ihrer regressiven Umwandlung. Während wir in den Knötchenherden ein Krümeligwerden und eine Auflösung des Gliaplasmas beobachten und in Zusammenhang damit auch degenerativen Zerfall an den Gliakernen bemerken, nehmen die Gliazellen, welche die eben genannten Herde zusammensetzen, bei ihrer regressiven Metamorphose Formen an, welche den hier normaler weise vorkommenden Gliazellty pen entsprechen. Es ist eine wichtige Eigentümlichkeit der Gliazellen in den Oberflächenzonen des Groß- und Kleinhirns, daß sie unter normalen Verhältnissen regressive Umwandlungen erfahren, besonders ein Schmal- und Dunkelwerden der länglichen Kerne bis zur Pyknose und eine Schrumpfung des Plasmaleibes und seiner Fortsätze, die 
spangenartig derb und knorrig werden. Mit Rücksicht auf die normalhistologischen Bilder aus jenen zentralen Zonen erscheint es nun sehr bedentungsvoll, daß die weichen und breiten, durch Stippchen gut gefärbten Plasmaleiber und Verbände schon sehr frühzeitig eine derartige Umwandlung erfahren, daß sie den Zellen, die hier normalerweise liegen, ähnlich und gleich werden. Abb. 29 illustriert das frühzeitige Auftreten einer derartigen regressiven Metamorphose an einzelnen Elementen, während die Hauptmasse der gewucherten Gliazellen mit ihren Verbänden noch in frischer progressiver Umwandlung sind. An den Rosettenherden des Großhirns tritt diese spezielle Art der regressiven Umwandlung ursprünglich progressiv veränderter Gliazellen mit außerordentlicher Schärfe und ebenfalls schon sehr frühzeitig zutage.

Wir kennen andere Beispiele für lokale Verschiedenheiten der pathologischen Gliawucherungen, die ebenfalls ihren tieferen Grund in den normalen Eigentümlichkeiten und der an Ort und Stelle gegebenen Anlage der gliösen Stützsubstanz haben.

Das gilt vor allem für die Neigung zur Gliafaserbildung unter pathologischen Verhältnissen. Ich erinnere nur an das auffälligste Beispiel, welches die multiple Sklerose und die Paralyse geben, vor allem, was die Herde in der Großhirnrinde betrifft. Ich konnte früher zeigen, wie für die seltenen, aber bedeutungsvollen Rinden markherde bei der Paralyse das gleiche gilt, wie für entsprechende Herde bei der multiplen Sklerose; während in den ausschließlich auf die Rinde beschränkten Entmarkungsherden die Gliafaserwucherung nur in der Oberflächenzone deutlich ist, sonst aber fast fehlt, zeigt in solchen Herden, wo der Entmarkungsbezirk von der Rinde in den Markradius übergreift, dieser Markanteil des Herdes im Gegensatz zu dem im Rindengrau gelegenen Herdabschnitt eine dichte Gliafaserwucherung entsprechend der normalen Anlage der faserigen Neuroglia in jenen Gebieten.

Hier - bei den atypischen Herden des Fleckfiebers - haben wir es nicht mit solcherlei Verschiedenheiten zu tun, die von der normalen Verteilung der faserigen Stützsubstanz abhängig sind. Die Besonderheit der Gliaherde und der regressiven Umwandlung der sie zusammensetzenden Gliazellen ist vielmehr an die lokalen Eigentümlichkeiten der zelligen Glia in der obersten Groß- und Kleinhirnrindenzone geknüpft: nämlich an die hier unter physiologischen Bedingungen vorkommende Gestaltung der Gliazellen und ihre regressiven Umbildungsformen. So haben wir hier ein anderes Beispiel für die Abhängigkeit der Art pathologischer Gliawucherung von der normaliter gegebenen Anlage der Neuroglia an Ort und Stelle. 
Wenn so das histologische Studium des Fleckfiebers für eine ganze Reihe histologischer Einzelsymptome, denen wir oft bei Rindenkrankheiten begegnen, von Wichtigkeit ist, so hat die Anatomie des Prozesses auch mit Rücksicht auf zwei allgemeinere anatomische I'ragen ihre hohe Bedeutung. Zunächst für die Frage der Rubrizierung der Prozesse. Man sieht auch hier wieder, daß nichts dabei herauskommt, wenn man einen vielgestaltigen anatomischen Prozeß dahin vergewaltigt, daß man ihn unter Berufung auf die Ätiologie in eine bestimmte Rubrik zwängt. Die den Psychiater und den Rindenanatomen so besonders interessierenden syphilogenen Prozesse sind hier ein hervorstechendes Beispiel. Seit langem wußten wir, wie ungeheuer verschiedenartig - pathologisch-anatomisch betrachtet - die Wirkungsweise der Syphilis im Organismus ist. Und dennoch konnte es geschehen, daß unter dem Einfluß der Entdeckung Noguchis sich mancher das histopathologische Problem der Paralyse auf die einfachste Art gelöst darstellte. Als ob Aufschlüsse über die Ätiologie - so ungeheuer wichtig sie sind - pathologisch-anatomische Tatsachen und Probleme aus der Welt schaffen könnten. Oder als ob sie die histopathologische Analyse nun überflüssig machten. Wenn man bei der Paralyse, gleichviel wie die Wirkungsweise der Spirochäten sein mag, rein histopathologisch die diagnostisch vor allem wichtigen diffusen Entzündungsvorgänge von den selbständigen (und nicht zu den entzündlichen Alterationen gehörigen) Degenerationsvorgängen unterscheidet, so muß man ja ähnliche Trennungen auch bei anderen komplexen Prozessen machen. Gewiß gibt es Krankheiten, die man restlos in bestimmte, allgemein pathologische Rubriken unterbringen kann. Aber wer einmal versucht hat, sich vielleicht eine Einteilung der verschiedenartigen zentralen Prozesse nach den wichtigsten, allgemein pathologischen Syndromen zu machen, wird die ungemeinen Schwierigkeiten der Klassifizierung kennen. Immerhin gibt es eine erhebliche Reihe von Prozessen, die zwanglos darin aufgehen, die man, wie zum Beispiel die Schlafkrankheit, als eine diffuse Encephalitis bezeichnen oder wie die Poliomyelitis als eine Entzündung im Rückenmark aufführen kann. Das gilt weiter vor allem von den durch Zirkulationsstörung bedingten anatomischen Bildern. Aber wie viel schwerer ist es schon bei den sog. degenerativen Prozessen. Wer aber das ätiologische Einteilungsprinzip für die pathologische Anatomie verwenden wollte, würde die anatomisch heterogensten Dinge miteinander vereinigen und histologisch gleichartige voneinander trennen müssen. Oskar und Cécile Vogt haben jüngst mit Recht vor der UUberschätzung des ätiologischen Prinzips gewarnt und den überragenden klassifikatorischen Wert der pathologischen Anatomie gegenüber der Ätiologie betont.

So wäre es denn auch verfehlt, wollte man das Fleckfieber lediglich 
als eine Entzündung bezeichnen - es sei denn, daß man den Begriff der Entzündung so unendlich weit faßt, daß man jede Reaktion des Organismus auf äußere Schädlichkeiten mit diesem Namen belegt. Aber dann wäre es - wie Nissl mit Thomas früher gesagt hat besser, daß man den Namen Entzündung ganz abschaffte. Bei ihrer Begriffsbestimmung wird man sich außer an die wichtigen biologischen bzw. funktionellen Eigentümlichkeiten der Entzündung, die Aschoff letzthin nachdrücklich betont hat, auch an die morphologischen Kriterien halten müssen, wie ich sie in meinen früheren Arbeiten in Anlehnung an Nissl, Lubarsch, Schridde u. a. besprochen habe. Wir treiben ja in der pathologischen Anatomie eben Histologie, d. h. Morphologie und müssen uns vor allem nach dem richten, was wir sehen. Und das wird für die Begriffsbestimmungen um so wesentlicher sein, als wir vielfach bezüglich der Leistungen pathologischer Gewebsprozesse über Vermutungen vorerst nicht hinauskommen. Wir sehen es den Dingen nur allzu oft nicht an, was sie funktionell bedeuten.

Wir fanden, daß die Mehrzahl der Fleckfieberherde sich lediglich in der Form reiner circumscripter Gliazellw ucherungen darstellt, daß ihnen die Beimischung weißer Blutelemente oder flüssiger Exsudatmassen durchaus fehlen kann. Ich sehe nicht, woher man das Recht nehmen sollte, diese Herde als entzündlich zu bezeichnen, wenn man sich nicht dem ätiologischen Bewertungsprinzip bedingungslos verschrieben hat. Dann wieder fanden wir Herde, in denen frühzeitig, in ihren jüngsten Stadien, massenhaft Leukocyten neben wuchernden Gliazellen lagen. Hier ist es gewiß berechtigt, von ent.zündlichen Herden zu sprechen; neben einer geringfügigen alterativen Schädigung sehen wir ein zelliges Exsudat und eine Proliferation seßhafter Elemente. Dann kamen die Bilder älterer Herde mit regressiven Umwandlungen, wo den Gliazellen vereinzelte Leukocyten und etwas zahlreichere, bald zerfallen de lymphocytäre Elemente bzw. diese allein beigemischt sind. Mag es für einen Teil von ihnen gelten, daß sie sich aus ursprünglich leukocytenhaltigen Herden entwickelt haben und daß hier auf das leukocytäre Anfangsstadium die lymphocytäre Reaktion gefolgt ist, mag also ein Teil dieser Herde ebenfalls als entzündlich gelten, so kann doch, wie ich ausführte, für einen anderen Teil von ihnen eine solche Entstehung nicht angenommen werden. Die Beimischung einzelner Leukocyten und Isymphocyten hat wohl keine weitere Bedeutung, als daß hier mit dem Zerfall des Herdzentrums solche Elemente einwandern, wie wir das ja bei allerhand rasch verlaufenden regressiven Umwandlungen und auch bei der Reparation sehen. - Ausgesprochen entzündlich sind wieder die diffusen Einscheidungen der Gefäße mit Lymphocyten und Plasmazellen 
und das lymphocytäre Infiltrat der Meningen. Erscheinen diese a usgebreiteten Zellexsudate ohne engeren Zusammenhang mit der Herdbildung, so weisen die mehrfach erwähnten Infiltrationen, von denen nur ein in der Nähe des Herdes gelegenes Gefäß betroffen ist, darauf hin, wie sich außerhalb der oft nicht entzündlichen Herdbildung doch mit ihr in lockerem Zusammenhang stehend ein exsudativer Vorgang abspielen kann. - Endlich wird das Bild noch durch die allgemeinen leichten Zerfallserscheinungen am funktiontragenden nervösen Gewebe, die außerhalb aller Herd- und Entzünqungsprozesse vor sich gehen, vervollständigt.

Es ist also unrichtig und auch zwecklos, dem so vielgestaltigen Bilde des Fleckfiebers e ine bestimmte Etikette anzuheften. A usges prochen entzündliche diffuse Veränderungen gehen neben reinen herdförmigen Proliferationen: und neben den nicht entzündlichen herdförmigen Wucherungen steht die entzündliche Herdentwicklung. Umschriebene Exsudationen kommen in der Nähe circumscripter reiner Proliferationen vor. Diese auBerordentliche Vielgestaltigkeit und vor allem die scheinbar so auffällige Gegensätzlichkeit zwischen einer nicht exsudativen Herdproliferation und einer durchaus entzündlich gestalteten Herdveränderung lehrt wieder, daß das gleiche, ursächliche Agens Veränderungen verschiedener morphologischer Dignität bewirken kann und daß alles natürliche Geschehen ,Ubergang" ist.

Und doch kann uns diese in dem fließenden Geschehen der Natur begründete Eigentümlichkeit nicht hindern, auch weiterhin Gruppen von Symptomenbildern herauszuheben; denn unbeschadet aller Utbergänge existieren doch Gruppen, über die eine Verständigung möglich sein sollte.

Der Befund einer reinen Gliawucherung in Herdform stellt uns endlich vor die Erörterung der prinzipiell bedeutungsvollen letzten Frage, ob es selbständige Gliawucherungen gibt. Kann ein Reiz eine Wucherung der Glia unmittelbar hervorrufen und ist zu einer Vermehrung der Gliazellen ein primärer Zerfall des funktiontragenden nervösen Gewebes nicht unbedingt notwendig? Gemeinhin ist es ja so, daß die Neuroglia einen Defekt deckt, daß sie die Aufgabe der Reparation oder Organisation hat und die gliöse Ersatzwucherung den Gleichgewichtszustand der Gewebe wiederherstellt. Und für den Rindenpathologen ist ja besonders die Tatsache von Wichtigkeit, daß überall, wo nervöses Gewebe zugrunde geht, die Neuroglia in allerdings qualitativ und quantitativ sehr verschiedener Form bei den einzelnen Prozessen progressive Umwandlungen erfährt. Jeder kennt die außerordentliche Bedeutung, welche diesen feineren gliösen Wuche- 
rungserscheinungen zukommt; wie sie einen Index für das Zugrundegehen funktiontragenden Parenchyms auch dort geben, wo wir - wie so häufig - die unmittelbaren Zerfallsvorgänge an der nervösen Substanz histologisch nicht darzustellen und zu erkennen vermögen. Ich erinnere nur daran, was uns $\mathrm{N}$ iss $\mathrm{l}$ gelehrt hat, und eine wie mächtige Förderung die Rindenforschung nicht zum wenigsten dadurch erfahren hat, daß er immer wieder die Bedeutung der progressiven Veränderungen der Gliazellen in der Hirnrinde betonte. Hatte man früher nur die gliösen Fasern berücksichtigt, so lernte man — ganz besonders für die Hirnrinde - die plasmatischen Gliaveränderungen in ihrer Bedeutung kennen. Auf diesen Wegen oder Umwegen suchte Alzheimer mit neuen Methoden der Färbung gliöser Strukturen weiterzukommen, um daran die Veränderungen im nervösen Gewebe und den Ausfall von spezifisch nervösen Elementen zu erkennen. Seine Studien über die pathologische Neuroglia und über deren Beziehungen zum Abbauvorgang im nervösen Gewebe beziehen sich gerade auf diese besonderen Aufgaben der Glia, die ihnen beim Zerfall des funktiontragenden nervösen Parenchyms erwachsen.

Aber beim Fleckfieber liegen die Dinge - wenigstens zum Teil anders. Für den Nachweis der diffusen Ausfälle geben uns allerdings auch hier die ausgebreiteten proliferativen Vorgänge an den gliösen Elementen und die Abbauprodukte in der Umgebung der Gefäße, z. B. des Markes einen Maßstab. Dagegen wurde ja gerade für die Herde beim Fleckfieber betont, daß hier im Gegensatz zu der sehr starken Gliazellproliferation die nervösen Substanzen auffallend lange erhalten bleiben und daß die Abbaustoffe hier durchschnittlich gering sind. Es kann nach allem, was wir besprochen haben, füglich $n$ ich $t$ behauptet werden, daß die reine fleckförmige Gliawucherung lediglich die Reaktion auf einen primären Zerfall funktiontragender Nervensubstanz sei. Wir haben es hier mit einer Gliazellvermehrung zu tun, die unter Mitwirkung eines Reizes zustande gekommen ist. Es braucht kaum erwähnt zu werden, daß diese Art von Reizwucherung zu unterscheiden ist von anderen selbständig erscheinenden Gliawucherungen, etwa von denen, wie wir sie bei der jetzt so viel behandelten Pseudosklerose, tuberösen Sklerose usw. sehen. Denn gerade auch für die Pseudosklerose haben die jüngsten ausgezeichneten Untersuchungen von Bielschowsky dargetan, daß dieser Prozeß, ähnlich wie die tuberöse Sklerose, einen ,geschwulstmäßigen Einschlag ${ }^{6}$ besitzt. Nahe verwandt dagegen dürften die reinen Gliaherde der Gliazellproliferation bei manchen Entzündungen sein. Gerade bei den Typen, die wir als ,,proliferative Entzündung" bezeichnen, ist ja das Auffallende, daß die Gewebsneubildung weit über das Maß der Deckung des Defekts hinausgeht. Die Wucherungen im Verlaufe der Entzündung kommen 
wohl alle auf dem Boden einer starken Steigerung der cellulären Funktionen zustande (Borst). In dieser biologischen Reaktionsweise gleicht die nicht entzündliche Herdbildung beim Fleckfieber den herdförmigen Wucherungen bei der Entzündung. Und wir sahen ja gerade beim Fleckfieber, daß die Dinge, die wir sonst nach ihren morphologischen Symptomen auseinanderhalten, hier enge beieinander wohnen - ein Moment, das eben im gleichen Sinne, d. h. für nahe biologische Beziehungen spricht.

Es läge nahe zu sagen : also beweist gerade das die Zugehörigkeit auch der r e i n en Gliaherde zur Entzündung und lehrt, daß es eine proliferative Entzündung ohne alle Exsudation gibt. Aber wie steht es dann z. B. mit der anatomischen Bewertung gleichartiger Gliawucherungen beim Typhus abdominalis? Will man auch das „Entzündung“ nennen, wo wir doch bei dieser Erkrankung im Zentralorgan weit und breit nichts von Exsudation sehen? Wir würden damit den Entzündungsbegriff enorm überdehnen, und es würde wenig übrigbleiben, was man nicht zur Entzündung zu rechnen hätte. Mit solchen verwaschenen und über alles Maß dehnbaren Begriffen zu arbeiten wäre mindestens unzweckmäßig. Wenn wir das Gliastrauchwerk in der Kleinhirnrinde isoliert betrachten, können wir doch daran das Wesen einer entzündlichen, „,defensiven Reaktion“ (im Sinne Aschoffs) nicht erweisen, ebensowenig wie bei den gewöhnlichen typischen Gliaherden des Fleckfiebers.

Auch wenn wir uns gegenwärtig halten, daß wir heute noch nicht in der Lage sind, die Zerfallserscheinungen des funktiontragenden Parenchyms frühzeitig und ihrem Umfange entsprechend zu erkennen und daß wir auf den indirekten Nachweis des nervösen Ausfalls durch die Gliaveränderungen angewiesen sind, so dürfen wir doch sagen, daß die außerordentliche Gliazellwucherung in den Fleckfieberherden weit über das Maß einer reaktiven Vermehrung nuch einem etwaigen primären Zerfall nervöser Elemente hinausgeht.

Wir haben es bei diesen Gliawucherungen wohl auch mit dem Ausdruck einer funktionellen Reaktion auf den einwirkenden Reiz zu tun, wie es Borst für die spezifisch parasitären Reize hervorhebt. Das Gliagewebe ist eben nicht eine starre Stützsubstanz, die nur bei Störung des Gleichgewichts und der Gewebsspannung eine Ausgleichwucherung zu leisten vermag oder die nur die Aufgabe hat, das zerfallene Material zu entfernen, sondern die auch selbständig Reizen z u gängig ist. Sie kann unter manchen Bedingungen zur Proliferation angeregt werden. Ich hoffe, mich zu dieser Frage später noch eingehender äußern zu können. 
und ihre Bedeutung für die Histopathologie der Hirnrinde.

\section{Frklärung der Abbildungen auf Tafel I bis X.1)}

Tafel I.

Abb. 1. Übersichtsbild über die Verteilung der Herde in der Großhirnrinde bei einem Fall mit sehr reichlichen Hirnrindenherden. $p$ Pia. mit Zell. einlagerung; 6 sechste Brod mannsche Schicht (tiefe Rinde, Übergang zum Mark); $h$ Herde; ig mit Plasmazellen infiltriertes längsgetroffenes Gefäß; die kleinen Gefäße vielfach durch feine Infiltrate hervorgehoben.

Mikrophotogramm, Nisslpräparat. Fall $\mathrm{H}$.

Abb. 2. Übersichtsbild über die Verteilung der Herde im Kleinhirn bei einem Fall mit sehr reichlichen Kleinhirnrindenherden. $h$ typische Herde; ph Pol eines Herdes; st "strauchartige" Gliawucherung; ig infiltriertes Gefäß; $p l$ feiner Plasmazellsaum zwischen Pia und oberster Rinde. Zelleinlagerungen in die Piamaschen.

Mikrophotogramm, Nisslpräparat. Fall B.

Abb. 3. Übersichtsbild über die Verteilung von Herden im Kleinhirn und über das Verhalten der Meningen. In der Molekularzone mehrere typische Herde, vielfach die Gefäße infiltriert. Ferner je ein Herd $(h)$ im Markradius und in der Höhe der Purkin jeschen Zellen. $p h$ Pol eines Herdes. Die Pia enthält auf der Kuppe der Windungen vorwiegend Makrophagen, in den Falten zwischen den einzelnen Windungen daneben zahlreiche Plasmazellen (kleiner und dunkler!) in wechselnder Dichte.

Mikrophotogramm, Nisslpräparat. Fall B.

Abb. 4. Übersichtsbild über das Band der unteren Olive mit ihrer Umgebung. Zahlreiche typische Herde, überwiegend im Grau dieses Kernes. Viele mit Plasmazellen infiltrierte Gefäße auch im angrenzenden Markweiß.

Mikrophotogramm, Nisslpräparat. Fall B.

Abb. 5. Übersichtsbild über Herde und Infiltrationen in den unteren und seitlichen Partien der Brücke. $h$ Herde; $i g$ mit Plasmazellen infiltrierte Gefäße; $p$ Pia mit sehr geringer Zelleinlagerung.

Mikrophotogramm, Nisslpräparat. Fall Schw.

Abb. 6. Herd in der mittleren Rinde; in der Umgebung des Herdes ein stark infiltriertes Gefäß.

Mikrophotogramm, Nisslpräparat. Fall A.

\section{Tafel II.}

Abb. 7. Übersichtsbild über die Verteilung von diffusen Infiltraten in einer Großhirnwindung, in der nur rechts oben ein kleines Herdchen liegt. Die infiltrierenden Elemente sind Plasmazellen neben vereinzelten

1) Anmerkung bei der Korrektur: Bei der Reproduktion der Mikrophotogramme und besonders der Zeichnungen hat die Wiener Kunstanstalt leider versagt. Irrtümlicherweise wurden außerdem von ihr die von dem bekannten wissenschaftlichen Zeichner Herm Dirr hergestellten farbigen Vorlagen ledig. lich schwarz-weiß und in einem unzureichenden Verfahren wiedergegeben. Es sind deshalb die Einzelheiten, auf deren Illustration besonderer Wert gelegt worden war, an den Tafelabbildungen nicht zu erkennen, so z. B. die feineren Eigentümlichkeiten der Stäbchenzellen (Abb. 31), der Makrophagen und Plasmazellen (Abb. 32, 33), des gliösen Strauchwerkes (Abb. 28, 29, 30). Auch die Schwarzweiß-Zeichnungen (Abb. 22, 23, 24) sind unzulänglich reproduziert, ebenso ein beträchtlicher Teil der Mikrophotogramme, speziell die Serien $19 \mathrm{a}-\mathrm{g}$ und 20 a-c. - Von einer neuen Reproduktion wurde unter den heutigen Umständen zur Vermeidung weiterer Verzögerung abgesehen. 
Lymphocyten. Durch das Infiltrat werden die größeren und kleineren Gefäße der Rinde deutlich herausgehoben.

Mikrophotogramm, Nisslpräparat. Fall B.

Abb. 8. Übersichtsbild vom Zellgehalt der Pia über einem Sulcus. Die zum größeren Teile aus Makrophagen, zum kleineren aus Plasmazellen bestehende Zelleinlagerung setzt sich auf die Piafalte des Sulcus fort; hier überwiegen die Plasmazellen (dunkler gefärbt und kleiner als die Makrophagen). Einzelne mit Plasmazellen infiltrierte Gefäße in der Rinde.

Mikrophotogramm, Nisslpräparat. Fall B.

Abb. 9. Herd um den Teilungswinkel eines Gefäßes gruppiert. Das Gefäß teilt sich in zwei Äste. (An der Gefäßwand sieht man hier erhebliche, im Photogramm allerdings nicht deutlich hervortretende regressive Umwandlungen an Endothelzellen.)

Mikrophotogramm, Nisslpräparat. Fall B.

Abb. 10. Oberste Kleinhirnschicht. $p$ subpiale Randzone. Die Wand des Herdgefäßes und seine nähere Umgebung ist von einem Fibrinnetz durchzogen.

Mikrophotogramm, Weigertsche Fibrinfärbung. Fall Schw.

Abb. 11. Herd aus der Großhirnrinde mit nicht wesentlich veränderten Ganglienzellen in seinen Randpartien und mit zablreichen Stäbchenzellen in der Peripherie und Umgebung des Hordes.

Mikrophotogramm, Nisslpräparat. Fall $\mathrm{H}$.

Abb. 12. Herd aus dem Seitenstrang des Rückenmarks und ein mit Plasmazellen infiltriertes Gefäß, von dem (in anderen Ebenen) ein Seitenzweig durch den Herd führt. Der Herd fällt durch die sehr große Anzahl von Leukpcyten neben den gliösen Elementen auf.

Mikrophotogramm, Nisslpräparat. Fall A.

\section{Tafel III.}

Abb. 13. Gliafaserbild von einem Herde der Medulla oblongata und seiner Ungebung. Keine Gliafaserneubildung. Die Gliafasern sind im Bereiche des Herdes geschwunden.

Mikrophotogramm, Weigertsche Gliafaserfärbung. Fall B.

Abb. 14. Herd im Markscheidenbilde aus der Körnerschicht des Kleinhirns. An der Stelle des Herdes sind die Markfasern geschwunden.

Mikrophotogramm, Markscheidenfärbung am Gefrierschnitt. Fall K.

Abb. 15. Gliöses Strauchwerk in der Kleinhirnrinde. Die gewucherten Gliazellen in lockeren ausgedehnten plasmatischen Verbänden. Der etwa zwischen $x^{1}$ u. $x^{2}$ gelegene Bezirk ist in Abb. 29 (schräg gestellt) bei stärkerer Vergrößerung zeichnerisch wiedergegeben.

Mikrophotogramm, Nisslpräparat. Fall B.

Abb. 16. Gliöses Strauchwerk in der Molekularzone des Kleinhirns, ziemlich gut gegen die nicht veränderte Umgebung abgegrenzt. Die gewucherten Gliazellen zeigen breite plasmatische Verbände. In der obersten Partie bei $m$ Mitosen. Die Gefäße in diesem atypischen Herde sind klar zu verfolgen und erscheinen nicht verändert. Das mit $x^{1}-x^{2}$ bezcichnete Gebiet ist in der Abb. 28 zeichnerisch wiedergegeben.

Mikrophotogramm, Nisslpräparat. Fall B.

Abb. 17. Ansammlung von Makrophagen und Plasmazellen im gefäßführenden Bindegewebe eines durch Schrägschnitt (welcher die Umbiegungsstelle einer Markarterie und Markvene getroffen hat) vorgetäuschten „Gefäßpaketes" im Markweiß dicht unter der tiefsten Rinde. Im Photogramm 
treten die Plasmazellen vermöge ihrer starken Kern- und Plasmafärbung dunkel heraus, während die großen blasenförmigen Makrophagen blaß erscheinen.

Mikrophotogramm, Nisslpräparat. Fall H.

Abb. 18. Makrophagen in der Adventitialscheide eines Gefäßes des Markradius (dicht unter der Rinde). Die sehr großen, teils blasigen, teils polyedrischen Zellen enthalten verschiedenartige Einschlüsse (Zellen, Kernreste, Pigment). $l$ Lumen des Gefäßes; $e$ Endothel; $n$ Grenze der Gefäßscheide gegen das nervöse Gewebe.

Mikrophotogramm, -Nisslpräparat. Fall H.

\section{Tafel IV.}

Abb. 19a-19g. Serie zur übersichtlichen Darstellung zweier Herde aus der Brücke.

Mikrophotogramm, Nisslpräparat. Schnittdicke $15 \%$. Brückenserie von Fall Schw. Schnitt Nr. 11-17.

19a. Beginn eines Herdes in einem kleinen Brückenkern.

19b. Der Herd schon voll entwickelt; die Gefäße intakt.

19c. Der Herd wieder etwas kleiner als im voraufgehenden Schnitt. Rechts unten davon Beginn eines sehr kleinen Herdes.

19d. Der große Herd wieder weiter gewachsen. Der kleine Herd erreicht in diesem Schnitt seine größte Ausbildung.

19e. Der große Herd ähnlich wie auf dem vorhergehenden Schnitt. Reste des kleinen Herdes.

19f. Der große Herd nimmt an Volumen ab.

$19 \mathrm{~g}$. Unterster Pol des großen Herdes.

Tafel $\mathrm{V}$.

Abb. 20a-20c. Serie zur übersichtlichen Darstellung eines „Rosettenherdes“" in der obersten Rinde.

Mikrophotogramme von der obersten Großhirnrindenschicht. Fall H.

Nisslfärbung. Schnittdicke je $15 \mu$. Aus der photographischen

Serie ist hier nur jeder zweite Schnitt wiedergegeben.

20 a. Schnitt 9 der Serie. Unterer Pol des Herdes. $r$ gliöse Randzone gegen die Pia; $g$ GefäB im unteren Pol des Herdes. In der Umgebung wurstförmige gliöse Zellen mit weitreichenden plasmatischen Fortsätzen.

20 b. Schnitt 11 der Serie (d. h. also $30 \mu$ weiter). Volle Entwicklung des „Rosettenherdes“. Das Gefäß mit kleinen Gliazellen besetzt und von ihm ausgehend sehr zahlreiche stäbchen- und wurstförmige gliöse Elemente mit breitem, fortsatzreichem Plasma.

20c. Schnitt 13 der Serie. Oberer Pol des Herdes. Das von der Pia

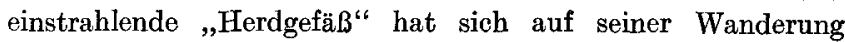
gegen die beiden vorhergehenden Bilder schon weit vom Rande entfernt. Es ist noch von einjgen gliösen Elementen umgeben. Im übrigen finden sich an diesem oberen Pol des Herdes, besonders zwischen dem Gefäß und der Randzone Reste der Gliazellwucherung.

\section{Tafel VI.}

Abb. 21 a-2l e. Serie zur übersichtlichen Darstellung der Änderung in der Gestaltung und Lage der Herde und des herdförmigen ,gliösen Strauchwerkes". Molekularzone des Kleinhirns. 
Mikrophotogramme, Nisslpräparate. Fall B. Schnitt 19-24. Schnittdicke beträgt durch die ganze Serie je $15 \mu$.

21 a. (Schnitt 19 der Serie.) Zeigt einen Herd $h^{\mathrm{L}}$ etwa in der Mitte der Molekularschicht. Die feine Streifung der Molekularzone in einzelnen Teilen des Präparates rührt von einer Zunahme des Plasmas der längsgestellten stäbchenartigen Gliazellen (mit kleinem länglichen Kern) her.

$21 \mathrm{~b}$. (Schnitt 21 der Serie.) Der Herd $h^{\mathbf{1}}$ ist klciner geworden und hat sich etwas verschoben. In $h^{2}$ sieht man den Pol eines Herdes, der in den folgenden Schnitten deutlicher wird. $s t r^{1}$ und $s t r^{2}$ gliöses "Strauchwerk" unabhängig von Herden ( $x$ Defekt in der Platte).

21 . (Schnitt 22 der Serie.) $h^{1}$ verschwindet allmählich; $h^{2}$ stellt sich als ausgesprochen kompakter Herd dar. An den Herden auf der Höhe ihrer Entwicklung heller Spalt bzw. helles Zentrum - häufiges Kunstprodukt infolge der Fixierung an dem sehr lockeren plasmareichen Herd. $s t r^{1}$ schwächer als im vorhergehenden Präparat, str ${ }^{2}$ dichter.

21 d. (Schnitt 23 der Serie.) $h^{1}$ fast ganz geschwunden, $h^{2}$ voll entwickelt, $s t r^{1}$ wieder etwas dichter, str ${ }^{2}$ lockerer und weiter ausgedehnt.

2le. (Schnitt 24 der Serie.) Letzte Spuren des Herdes $h^{1} ; h^{2}$ etwa wie im vorigen Schnitt, $s t r^{1}$ und $s t r^{2}$ in allmählichem Verschwinden.

\section{Tafel VII.}

Abb. 22. Herd um ein längs getroffenes Gefäß gruppiert, im Grau der Vierhügel. Starke Wucherung von Gliazellen, die nach der Peripherie stäbchenartig ausgezogen erscheinen. Die Gefäßwandzellen zum Teil von Gliaelemeten überlagert. An einer Stelle $m$ Mitose einer Gliazelle. ggl Ganglienzellen.

Nisslpräparat. Schwarzweiß-Zeichnung. Leitz' homogene Immersion, Ok. 1. Fall Schw.

Abb. 23. Pol eines Herdes $(h)$ mitten zwischen den Ganglienzellen der Hirnrinde. Daneben an einem anderen nicht zu dem Herde gehörigen Gefäß, Wucherung der Gefäßwandzellen lediglich auf der einen Seite der Gefäßwand. $p l$ Plasmazelle; st stäbchen- und wurstförmig ausgezogene Gliazellen. Auch außerhalb der herdförmigen Veränderung Wucherung der Neurogliazellen $(g l)$, welche Gruppen vielstrahliger Elemente mit weit verzweigtem, durch Stippchen verstärktem Plasma bilden.

Nisslpräparat. Schwarzweiß-Zeichnung. Leitz' Obj. 6. Ok. 3. Fall H.

Abb. 24. Gliöses Strauchwerk in der Molekularzone des Kleinhirns bei einem Fall von Typhus abdominalis. Die etwa in der Mitte dieser Schicht gelegene Gliazellwucherung mit ihren reichen protoplasmatischen Verbänden ist herdförmig und verliert sich ziemlich rasch gegen das normale Gewebe. Die im Schnitt gelegenen Capillaren sind normal.

Nisslpräparat. Zeichnung bei Leitz' Obj.6. Ok. 1. Fall F.

\section{Tafel VIII.}

Abb. 25 a u. 25 b. Schnitt 11 und 12 einer Kleinhirnserie. Der Herd liegt in der Molekularschicht des Kleinhirns. Das (einzige) Herdgefäß ist durch die beiden Schnitte hindurch genau zu verfolgen. In Schnitt $25 \mathrm{~b}$ hört es dort auf, wo sein Ende von der mit $x$ bezeichneten Gliazelle überlagert wird; es beginnt wieder in $25 \mathrm{~b}$ an der Stelle, wo eine degenerierte Glia- 
zelle $\left(x^{1}\right)$ dem Gefäß aufgelagert ist. Bei $y$ in $25 \mathrm{~b}$ Beginn einer Verzweigungsstelle des Herdgefäßes. - Gegen die oberhalb des Herdes gelegene Capillare $(c)$ in $25 \mathrm{~b}$ sieht man Protoplasmafortsätze der Gliazellen ziehen.

Nisslpräparat. Zeichnung bei Leitz' Obj. 6, Ok. 3. Fall B.

Abb. 26. Frischer, zahlreiche Leukocyten enthaltender Herd in der obersten Kleinhirnrinde. Einzelne Leukocyten sind auch außerhalb des Herdes im nervösen Parenchym verstreut. Der Herd erscheint noch locker und die Zellen wenig dicht. Die Zunahme des Gliaprotoplasmas auch an den wurstförmigen Zellen noch verhältnismäßig gering. $m$ Mitose einer Gliazelle.

Nisslpräparat. Zeichnung bei Leitz Immersion 1/12, Ok. 0. Fall Sch. Abb. 27. Alter Herd, bei dem der relativ geringe Kerngehalt des Zentrums des Herdes auffällt. Der Hauptteil des Herdes enthält Plasmamassen, die in deutlicher Verbindung miteinander stehen und welche Gliakerne führen. Zwischen den Plasmamassen helle Lücken, in denen sich färberisch nichts nachweisen läßt. In der peripheren Zone des Herdes reichlichere Gliazellen. Vereinzelte weiße Blutelemente; ly Lymphocyten; leu Leukocyten; $p l$ Plasmazellen mit undeutlicher Kernmembran und vorgebuchteten Chromatinbrocken; $p l^{\mathbf{1}}$ zerfallende Plasmazellen mit tief dunklem höckerigen Kern. Die Ganglienzellen zeigen keine gröberen Veränderungen des Kernes; nur die Nisslsubstanz ist undeutlich und die Konfiguration des Zelleibes durch die Herdmasse beeinflußt.

Nisslpräparat. Zeichnung bei Leitz Immersion $1 / 12$, Ok. 1. Fall Schw.

\section{Tafel IX.}

Abb. 28. Bezirk $x^{1}-x^{2}$ des Mikrophotogramms 16 bei Immersion gezeichnet. Gliöses Strauchwerk der Molekularschicht des Kleinhirns. $r$ Randzone gegen die Pia, $m$ Mitosen (die mittlere stellt vielleicht eine pluripolare Kernteilung oder eine Absprengung von Chromosomen vor). Die Gefäße sind scharfrandig, die Gefäßwandzellen ohne jede Veränderung. Die Fortsätze der breiten, weich in die Umgebung übergehenden Plasmabrücken der Gliazellen stehen großenteils miteinander in Verbindung und sind durch Stippehen hervorgehoben.

Zeichnung. Nisslpräparat. Fall B.

Abb. 29. Bezirk $x^{1}-x^{2}$ des Mikrophotogramms 15 bei Immersion gezeichnet. Neben den weichen und breiten plasmatischen Verbänden und den feineren Durchflechtungen der plasmatischen Glia sieht man regressive Umwandlungen einzelner Teile dieses gliösen Maschenwerks bei $r$ : längliche geschrumpft erscheinende Kerne und Verschmälerung des Zelleibes mit ziemlich scharfen und spangenartigen Fortsätzen. $s g l$ breiter syncytialer Verband von Gliazellen. cgl einer Capillare aufliegender gliöser Zug. $c$ Präcapillare.

Zeichnung. Nisslpräparat. Fall B.

Abb. 30. "Teil eines gliösen Strauchwerkes der Molekularschicht des Kleinhirns. $x$ dicht oberhalb der Purkinjeschen Zellen, $z$ dicht unterhalb der Pia gelegene Zone. Die Gliazellwucherung folgt hauptsächlich dem Verlauf einer Capillare, welche unterhalb der in der Zeichnung wiedergegebenen Ebene verläuft und welche mit der in $c$ längsgetroffenen Capillare aus dem Teilungswinkel bei $e$ (wo man eine Intimazelle sieht) entspringt. Das gliöse Protoplasma ist außerordentlich weit verzweigt 
und durch Stippehen hervorgehoben. st stäbchen- und wurstförmige Zellen; ly lymphocytäre Zelle.

Nisslpräparat, Zeichnung bei Leitz homogene Immersion $1 / 12 \cdot$ Ok. 0 . Fall B.

Abb. 3l. Stäbchenzellen, an welchen die außerordentliche Reichhaltigkeit der feinen Fortsätze auffällt; diese zeigen wiederum überall einen sehr feinen Spitzenbesatz, der sich unscharf gegen die Umgebung verliert. Das Plasma durch Stippchen hervorgehoben. Auffallende Breite des Plasmaleibes.

Nisslpräparat. Zeichnung bei Zeiß Apochrom $2 \mathrm{~mm}$. Ok. 4 . Fall H. und $\mathrm{B}$.

\section{Tafel $\mathrm{X}$.}

Abb. 32. Makrophagen und Plasmazellen in den Meningen. $g$ Meningealgefäße. Die Plasmazellen in verschiedenen Stadien ihrer Entwicklung (siehe auch Abb. 33). $m$ mitotische, am amitotische Kernteilung in den Makrophagen. Die Makrophagen enthalten Reste von roten Blutkörperchen, Pigment, Zellreste von der Gestalt der „Vogelaugen“, andere enthalten Vakuolen. $m p l$ Makrophagen mit eingeschlossenen Plasmazellen.

Nisslpräparat, Zeichnung bei Leitz Immersion, Ok. 0. Fall B.

Abb. 33. Plasmazellen in einer Piamasche. Entwicklung der Plasmazellen aus Lymphocyten: $l y$ Lymphocyt, $p l$ eine typische Plasmazelle; daneben Vorstufen von Plasmazellen (allmähliche Ausbildung des hellen Hofes); $p$ Piazellen.

Nisslpräparat. Zeichnung bei Leitz Immersion, Ok. 3. Fall B.

Abb. 34. Großhirnrindenherd mit lipoiden Abbauprodukten (häufiges Bild). Die Gliazellen des Herdes führen kleine Fetttröpfchen. In den Adventitial. elementen des in der Nähe befindlichen Gefäßes ebenfalls Fetttröpfchen. $x$ artifizieller Spalt infolge Retraktion der Randglia von der Adventitial. scheide. Die Wand des „Herdgefäßes" selbst ist nicht von lipoiden Massen durchsetzt.

Hämatoxylin-Scharlachrotfärbung. Zeichnung bei Leitz 6, Oc. 1. Fall Schw.

Abb. 35. Die Hälfte cines großen Herdes mit ungewöhnlich starken Zerfallserscheinungen (seltenes Bild). Die Gliaelemente sind von großen und zahlreichen Fetttröpfchen ausgefüllt. (Das größere „Herdgefäß“ mit starken regressiven Veränderungen ist in diesem Schnitt nicht mit getroffen.) In der peripheren Zone des Herdes und außerhalb davon sieht man in den Gliazellfortsätzen fein verteilte lipoide Stoffe.

Hämatoxylin-Scharlachrotfärbung. Zeichnung bei Leitz 6 . Ok. 3. Fall B.

Abb. 36. Gefäß aus dem Markradius. In dem Adventitialraum und außerhalb davon in der Glia perivascularis mit Fetttropfen angefüllte Körnchenzellen. $a$ außerhalb des Adventitialraumes in der Randzone gelegene, $b$ in der Adventitialscheide gelegene mit Fett beladene Zellen.

Hämatoxylin-Scharlachrotfärbung. Zeichnung bei Leitz 6, Ok. 1. Fall B. 